Revista de Estudios Histórico-Jurídicos

[Sección historia del derecho patrio chileno]

XXXIX (Valparaíso, Chile, 2017)

[pp. 299 - 328]

\title{
UNA PROPUESTA DE RECONSTRUCCIÓN DEL SENTIDO ORIGinal DEL ESTADO CIVIL EN EL Código Civil CHILENo
} [A proposal for the reconstruction of the core sense of the marital status in the Chilean Civil Code]

\author{
Juan Luis Goldenberg SerRano* \\ Pontificia Universidad Católica de Chile
}

\section{RESUMEN}

El presente artículo plantea una reconstrucción del concepto de e $\mathrm{s} \mathrm{tad} \mathrm{o}$ c ivil en la forma prevista en el Código Civil chileno a partir de un análisis histórico y sistemático de las normas contempladas en su texto original. Lo anterior, a efectos de invalidar las críticas que la mayor parte de la doctrina nacional ha formulado a su respecto que, a nuestro juicio, han terminado por vaciarlo de contenido y, peor aún, han llevado a nuestro legislador a proponer reelaboraciones erróneas en las modificaciones posteriores.

\section{Palabras clave}

Estado civil - Capacidad - Potestad marital - Autoridad paterna - Patria potestad.

\section{Abstract}

This article proposes a reconstruction of the concept of civil status as it is established in the Chilean Civil Code, based on both a historical and systematic analysis of the rules included in its original text. The foregoing in order to invalidate the criticism that most of the national authors have expressed in such regard, that, in our opinion, have ended up emptying it of content and, even worse, have led our legislator to propose erroneous reelaborations in the later modifications.

\section{Keywords}

Civil status - capacity - marital power - parental authority - parental rights.

RECIBIDO el 4 de mayo y ACEPTADO el 7 de julio de 2017

* Profesor del Departamento de Derecho Privado de la Pontificia Universidad Católica de Chile. Avenida Libertador Bernardo O'Higgins 340, Santiago. Correo electrónico: jgoldenb@ uc.cl 


\section{INTRODUCCIÓN}

Si existe una definición legal que ha sido claramente rechazada por la mayor parte de la doctrina nacional, esta es la del e s t a d o c i vil, en la forma en la que ella aparece establecida en el artículo 304 del Código Civil, disponiendo éste que "el estado civil es la calidad de un individuo, en cuanto le habilita para ejercer ciertos derechos o contraer ciertas obligaciones civiles", nuestra doctrina ha dado cuenta de la vaguedad del concepto y de la falta de indicación de sus características clásicas $^{1}$; de su posible confusión con otras figuras jurídicas, como la nacionali$\mathrm{dad}^{2}$ o la capacidad ${ }^{3}$; e, incluso, del hecho que ella no guarda congruencia con la regulación que sigue al referido artículo, de manera que no resulta indicativa de sus efectos propios, generalmente relacionados a los derechos y obligaciones asociadas al estado ${ }^{4}$.

A partir de dichas críticas, se ha tendido a aceptar la definición alternativa propuesta por Somarriva conforme a la cual el estado civil sería "la posición y calidad permanente que ocupa una persona en la familia y en la sociedad, de la cual se derivan para ella derechos y obligaciones"5. A nuestro juicio, esta construcción paralela ha desembocado en un vaciamiento de su sentido jurídico. Con ello, se ha hecho realidad la crítica que había formulado Savigny, desestimando el carácter técnico del estado, sólo refiriendo a una posición en la sociedad en la que escasamente puede apreciarse una consecuencia jurídica más allá de la indicación de un cierto régimen aplicable ${ }^{6}$. Sin embargo, más grave aún, esta transformación doctrinal ha conllevado a una errónea reelaboración del estado civil en diversos textos normativos, sin que se hayan efectuado esfuerzos para la revisión de su sentido histórico.

La hipótesis con la que trabajamos es que la definición prevista en el artículo 304 CC estaba correctamente construida en la configuración original de nuestro Código Civil, expresándose como aquellas circunstancias que, derivadas de la posición del individuo en sus relaciones familiares, lograban alterar las reglas generales de la capacidad de ejercicio. Ella es expresiva, a su vez, de su necesaria reconstrucción una vez que el ordenamiento civil ha reconocido una igualdad de las personas, como se advierte especialmente del artículo $55 \mathrm{CC}$, de manera que el

${ }^{1}$ Ramos Pazos, René, Derecho de familia (séptima edición actualizada, Santiago, Editorial Jurídica de Chile, 2010), II, p. 527; Ducci Claro, Carlos, Derecho civil. Parte general (cuarta edición, Santiago, Editorial Jurídica de Chile, 2015), p. 131.

2 Somarriva Undurraga, Manuel, Derecho civil. Derecho de familia (Santiago, Dirección General de Prisiones, 1933), p. 601.

3 Alessandri Rodríguez, Arturo; Somarriva Undurraga, Manuel; Vodanovic Haklicka, Antonio, Tratado de derecho civil. Partes preliminar y general (Santiago, Editorial Jurídica de Chile, 1998), I, p. 433.

4 Vodanovic Haklicka, Antonio, Manual de derecho civil. Parte preliminar y general (Santiago, LexisNexis, 2003), I, pp. 138, 234 y 236.

5 Somarriva Undurraga, Manuel, cit. (n. 2), p. 601; en un sentido bastante próximo, también Alessandri, Somarriva y Vodanovic, cit. (n. 3), I, p. 433.

${ }^{6}$ SAVIGnY, Friedrich Karl von, Sistema del derecho romano actual (trad. Jacinto Mesía y Manuel Poley, segunda edición, Madrid, Centro Editorial de Góngora, 1839-1847), I, p. 436. 
status ya no puede ser concebido como un medio de discriminación de las personas desplegado en un nivel sustantivo, especialmente en lo relativo a su capacidad de goce. Y, a su vez, se diferencia de la capacidad de ejercicio puesto que se contempla formulado a partir de una noción de dependencia que podía justificarse en razón de las reglas originales del matrimonio o de la filiación legítima o natural.

Si bien es evidente que las referidas situaciones de dependencia, advertidas principalmente en razón de la potestad marital, de la autoridad paterna y de la patria potestad, han mutado de modo considerable desde la vigencia del código, ellas no se han visto correctamente replicadas al tiempo de revisar el concepto de estado civil ${ }^{7}$. Sin embargo, por el momento no nos interesa revisar este tema, puesto

7 Para estos efectos, deberán considerarse las reglas que han incidido en la comprensión del estado civil, incluyendo especialmente el decreto ley $\mathrm{N}^{\circ} 328$, de 29 de abril de1925, que incorporó nuevas reglas relativas a la capacidad de la mujer y al ejercicio de la patria potestad; la ley $\mathrm{N}^{\circ} 4.808$, de reforma de la ley de registro civil, de 10 de febrero de 1930 (en adelante, la LRC); la ley $\mathrm{N}^{\circ}$ 5.521, de 19 de diciembre de 1934, principalmente en cuanto incorporó el régimen del patrimonio reservado de la mujer casada en sociedad conyugal, permitió el pacto de separación de bienes en el marco de las capitulaciones matrimoniales y reformuló nuevamente normas relativas al ejercicio de la patria potestad; la ley $\mathrm{N}^{\circ} 7.612$, de 21 de octubre de 1943, en tanto rebajó la mayoría de edad a los veintiún años, eliminó la habilitación de edad, reformuló la incapacidad de la mujer casada en sociedad conyugal y permitió la sustitución del régimen de sociedad conyugal, incluso, por la separación total de bienes durante la vigencia del matrimonio; la ley $\mathrm{N}^{\circ} 10.271$, de 2 de abril de 1952, que especialmente reformuló el tratamiento de la filiación natural; la ley $\mathrm{N}^{\circ} 18.802$, de 9 de junio de 1989, que reconfiguró íntegramente el modelo de capacidad de la mujer casada en sociedad conyugal; la ley $\mathrm{N}^{\circ} 19.221$, de 1 de junio de 1993 , que nuevamente rebajó la mayoría de edad, ahora a dieciocho años; la ley $\mathrm{N}^{\circ} 19.335$, de 23 de septiembre de 1994, que creó un nuevo régimen alternativo denominado "participación en los gananciales" e incorporó la regulación de los bienes familiares; la ley $\mathrm{N}^{\circ} 19.585$, que reformuló el sistema filiativo chileno; la ley $\mathrm{N}^{\circ}$ 19.947, de 17 de mayo de 2004 (en adelante, la NLMC), que, para lo que nos interesa, introdujo la posibilidad de divorcio vincular y reguló la separación legal de los cónyuges, reconociendo el estado de divorciado y separado judicialmente (aunque este último es discutido en doctrina y jurisprudencia), y haciendo referencias a un estado de soltero; y la ley $\mathrm{N}^{\circ} 20.830$, de 22 de octubre de 2015, que reguló el denominado "acuerdo de unión civil" reconociendo el estado civil de convivientes civiles. A ello debemos añadir el proyecto de ley que pretende modificar el Código Civil y "crear el estado civil de soltero y su medio de prueba” (Boletín 8239-07).

A partir de los cuerpos legales antes citados puede concluirse que constituirían actualmente e s t a d o c i v i l, los siguientes: (i) en razón de la filiación, los de p a d r e, m a d r e e h i j o (artículo 305 CC); (ii) en razón de la situación conyugal, los de c a s a d o (artículos 305 CC y 37 y 38 de la NLMC), s e p a r a d o j u d i c i a 1 m e n t e (artículos 305 CC y 6 de la NLMC), v i u d o (artículos 305 CC, 9 de la NLMC y 39.3 de la LRC) y d i v o r c i a d o (artículos 305 CC, 9 y 59 de la NLMC); y (iii) en razón de la celebración de un acuerdo de unión civil, el de c o n v i vi e n t e c i vi 1 (artículo 1 de la ley $\mathrm{N}^{\circ}$ 20.830). Más dudas plantea la existencia del estado civil de s o 1 t e $\mathrm{r}$ o , toda vez que no se encuentra referido en el Código Civil y existe el proyecto de ley, antes referido, que pretende su c r e a c i ó n . Lo anterior, no obstante algunas referencias indirectas al estado de soltero que se disponen en los artículos 9 de la NLMC y el artículo 39.3 de la LRC.

Ahora bien, si se observa todo lo anterior, en línea con la tesis que se sostiene en el presente trabajo, se presentan variadas inconsistencias que dificultan justificar la referencia al estado en aquellas situaciones en las que no se produce una alteración de las reglas de capacidad de ejercicio. Así, a contar del otorgamiento de la plena capacidad de la mujer casada en sociedad conyugal, 
que estimamos que es previamente necesario dar cuenta de su sentido original en el CC para que, en un estudio posterior, puedan señalarse las mutaciones en el derecho de familia que han tenido indudable trascendencia en lo referente a la modulación de las reglas de la capacidad de ejercicio de una persona en virtud de la integración a un grupo familiar ${ }^{8}$.

Para el cumplimiento del citado objetivo, el camino propuesto es el siguiente: primero, nos referiremos a la inestabilidad del concepto de estado civil en atención a las continuas reformulaciones históricas de los diversos contextos sociales en los que se sitúan los individuos (II); luego desarrollaremos el concepto de estado civil contraponiéndolo a la definición de persona que encontramos en nuestra codificación civil (III); y, finalmente, propondremos una nueva lectura de la definición contenida en el artículo 304 CC, por medio del desglose de sus elementos y una interpretación sistemática de las normas del Código original (IV); todo ello para terminar con las conclusiones de rigor.

\section{LA INESTABILIDAD DEL CONCEPTO DE ESTADO CIVIL:}

\section{RECONDUCCIONES A LA FORMULACIÓN SOCIAL SUBYACENTE}

El problema de la delimitación del concepto de estado civil se refiere principalmente a un asunto de fuentes y a las continuaciones variaciones que ha experimentado la estructura social desde Roma, desde donde pueden rastrearse sus orígenes, hasta nuestros días9. Las dificultades técnicas que se revelan del estudio de tales fuentes refuerzan tal aseveración al tiempo en que los criterios considerados para dar cuenta de la posición social del individuo se presentan

por medio de la ley $\mathrm{N}^{\circ} 18.802$, el estado civil basado en el matrimonio sólo tendría algún sentido indicativo para el caso en que se aludiera a las limitaciones emanadas de la administración de tal sociedad y de los bienes propios de la mujer, pero ello no se conjugaría correctamente con todas las posibilidades que actualmente se despliegan en las normas pertinentes, especialmente en relación con la diversidad de regímenes matrimoniales. Más acusado parece el desajuste en materias como las relativas a la separación judicial, salvo por la referencia al término del régimen existente entre las partes (art. 34 de la NLMC), con el mismo alcance antes señalado; a las relativas a la convivencia civil, que en caso alguno producen una alteración de la capacidad jurídica de las partes, agregándose, además, que se trataría del único supuesto en que el estado puede ser terminado por la sola voluntad de los particulares, sin mediar sentencia judicial, y, además, con efectos retroactivos (artículos 1, 26, d) y e) de la ley $\mathrm{N}^{\circ} 20.830$ ); y a la soltería, que, a nuestro juicio, es indicativo de una completa ausencia de estado civil en razón de la situación conyugal y, ahora, de convivencia civil, del individuo, indicativo también de la falta de membresía a un grupo familiar por esta causa (perviviendo, sin embargo, la que puede derivar de las relaciones paterno-filiales, como las de padre, madre o hijo).

Para un estudio actualizado de la situación del estado civil en la legislación nacional, vid. Rivero Ferrada, Carolina, El estado civil, en Del Picó Rubio, Jorge (dir.), Derecho de familia (Santiago, Thomson Reuters, 2016), pp. 647-664.

${ }^{8}$ En este sentido, todas las referencias efectuadas en este artículo a las normas contenidas en el Código Civil lo son a su texto original, con excepción de las normas citadas en la nota inmediatamente anterior.

9 De Castro y Bravo, Federico, Derecho civil de España (Madrid, Instituto de Estudios Políticos, 1952), II, pp. 58-60. 
de modo heterogéneo y, por supuesto, variable ${ }^{10}$. Desde el momento en que la construcción jurídico-política de la sociedad ha mutado en sus esferas mayores, también lo han hecho las agrupaciones más nucleares, como son las que derivan especialmente de las relaciones de familia.

Durante larguísimo tiempo, la mentada individualidad no era considerada como un estadio previo al estado civil, sino como resultado de ella, posando entonces la mirada en su configuración asociativa y en sus efectos jurídicos. Es esta forma de concebir al ser humano la que no ha permanecido en la variable del tiempo, desplegándose de uno u otro modo dependiente del momento histórico en el que nos situemos. Ante tales vaivenes no queda duda que un concepto que se sustenta en la posición que ocupa el individuo ante tales agrupaciones debe seguir reconducciones que resulten consistentes con las reformulaciones del tejido social, lo que se justifica las mencionadas dificultades para fijar las fronteras del estado civil. Entonces, el estado civil nunca se articula de modo aislado, sino que se ubica como una abstracción de todos aquellos aspectos que nos condicionan en la vida en sociedad. Por ello, no se ha planteado necesariamente como único e inmutable, sino que sus contenidos dependen de las organizaciones sociales en las que el individuo se encuentre inmerso y la forma en que éstos se construyen, ponderando los factores que puedan resultar relevantes desde un punto de vista jurídico, sea desde una perspectiva pública o privada.

El punto de partida a este respecto se centró en la idea de la capacidad natural, iniciada con el nacimiento y extinguida con la muerte ${ }^{11}$, que en el derecho romano podía ser alterada en razón de las clasificaciones entre liberi y servi ${ }^{12}$; cires, latini o peregrine; y sui iuris y alieni iuris, dando lugar a los diversos factores determinantes de la capitis diminutio (a la vez, máxima, media y mínima) ${ }^{13}$. A partir de tal tripartición, se dio curso a las denominaciones (no romanas, como apunta Kaser ${ }^{14}$ ) de status libertatis, status civitatis y status familiae, que, ponderados en razón de diversas esferas, resultaban alusivos a la graduación de tal capacidad. Pero, como agrega Kaser, "status no es capacidad jurídica, sino más bien la situación jurídica de un hombre" 15 , como una referencia a aquellos factores que son considerados a efectos de ofrecer una distinción entre aquellos, incidiendo, entonces, como un medio de graduación de tal capacidad. Ya Savigny nos indicaba que "para comprender bajo una base común estos grados diferentes, se puede considerar el estado del individuo como una disminución de capacidad, lo cual comprende

${ }^{10}$ Sobre la vaguedad del concepto de estado, vid. Hoyos CASTAN̄EDA, Ilva Myriam, El concepto jurídico de persona (Pamplona, Ediciones Universidad de Navarra, S.A., 1989), pp. 119-124.

11 SavignY, Friedrich Karl von, cit. (n. 6), I, pp. 305 y 313.

12 A partir de Gai. 1,8 ss., sobre la tripartición de personae, res y actiones; y Gai. 1,48, sobre las divisiones de las personas según su status. Sobre esta materia, vid. STAGL, Jakob F., De cómo el hombre llegó a ser persona: los orígenes de un concepto jurídico-filosófico en el derecho romano, en Revista de Derecho de la Pontificia Universidad Católica de Valparaíso, 45 (2015), pp. 378-382.

13 SAVIGNY, Friedrich Karl von, cit. (n. 6), I, pp. 316-337.

${ }^{14}$ Kaser, Max, Derecho romano privado (Madrid, Reus, 1968), p. 70.

15 Ibíd. 
también la pérdida completa de ella"16. Conforme a ello, ya Heineccius indicaba que "quicunque nullo statu gaudet, iure Romano non persona, sed res habetur" ${ }^{17}$.

La multidimensionalidad de los factores de graduación en Roma, traslapado con las ideas de caput y condición ${ }^{18}$, permitirían apreciar el punto a partir del connubium, como capacidad de contraer matrimonio, y el commercium, como facultad de enajenar mediante la mancipatio, y la forma en la que estas posibilidades se ordenaban en relación con la posición del individuo en sus esferas sociales ${ }^{19}$. Sin embargo, a todo ello se fue agregando una variante adicional, como era aquella que terminaba por ofrecer un paralelo entre la idea de la persona y su propio estado, operando éste, en consecuencia, en un nivel sustancial en la identificación del ser humano. Sin embargo, la noción de persona no parecía necesariamente vinculada a una situación de libertad ${ }^{20}$, como aparece tanto en la propuesta de división de $\mathrm{Gayo}^{21}$, como en los textos de Justiniano ${ }^{22}$, admitiendo ambos la división de las personas en libres y esclavos. Así, se llegó a considerar que el esclavo podía ser considerado como persona, en razón de su individualidad (esto es, desde el punto de vista meramente natural), pero no por tal motivo obtenía una capacidad natural (ahora, desde el punto de vista civil) ${ }^{23}$. Estaba, en otros términos, limitado por una incapacidad general, privándosele, en consecuencia, de toda posibilidad de matrimonio (y, por tanto, de parentesco) y de propiedad ${ }^{24}$. Si la primera clasificación de los seres humanos se basaba en su libertad, ofreciendo también justificaciones para la objetivización de un cierto grupo, el status libertatis pasó a asumirse como un elemento integrante en la construcción de la personalidad.

Conforme a ello, se ofrecía la conceptualización de la personalidad como la

16 SAVIGNY, Friedrich Karl von, cit. (n. 6), I, p. 316.

17 HeIneccius, Johann Gottlieb, Elementa iuris civilis secundum ordinem institutionum (Giessa, Krieger, 1767), p. 44; traducción disponible en HeInECIO, Elementos del derecho romano según el orden de las instituciones (traducción de José Vicente, Madrid, Imprenta de Don Pedro Sanz y Sanz, 1982), p. 23, del siguiente tenor: "de aquí el axioma jurídico: que por derecho romano el que no goza de ningún estado no es considerado como persona sino como cosa".

18 Respecto a la incidencia de estos conceptos en la construcción del derecho de la persona, vid. BARRIENTOS GRANDÓn, Javier, Sobre el 'espacio' y el 'tiempo' y el 'estado de las personas'. Una mirada desde la historia del derecho, en MecCarelli, Massimo y Solla SASTRE, María Julia (eds.), Spatial and Temporal Dimensions for Legal History. Research Experiences and Itineraries (Frankfurt am Main, Max Planck Institute for European Legal History, 2016), p. 65. Sobre los errores comunes manifestados en la época sobre este punto, una dura crítica es observable en SAVIGNY, Friedrich Karl von, cit. (n. 6), I, p. 317, especialmente en su interés de construir un sistema coherente del derecho romano, considerando, eso sí, sus mutaciones en el tiempo.

19 SAVIGNY, Friedrich Karl von, cit. (n. 6), I, p. 318; STAGL, Jakob F., cit. (n. 12), p. 382.

${ }^{20}$ Sobre la evolución del derecho romano en este punto, vid. STAGL, Jakob F., cit. (n. 12), pp. 385-386.

21 Ver cita 12.

22 J. 1,2,12. ("Prius de personis videamus. Nam parum est ius nosse, si personae, quarum causa statutum est, ignorentur").

${ }^{23}$ Heinnecius, Johann Gottlieb, cit. (n. 17), p. 45. Para un amplio estudio de la cuestión, puede consultarse a GUZMÁN BRITO, Alejandro, La igualdad natural de todos los hombres en el pensamiento jurídico romano de la época clásica, en Revista de Estudios Histórico-Jurídicos, 14 (1991), pp. 17-42.

${ }^{24}$ SAVIGNY, Friedrich Karl von, cit. (n. 6), I, p. 321. 
m á s c a r a que permitía el desenvolvimiento del personaje en la esfera social ${ }^{25}$, dando una cobertura civil al hombre en clave de capacidad. Esta construcción se extendió en la formulación del concepto de persona en el derecho intermedio, quedando planteada por Heineccius bajo la reconocida referencia conforme a la cual "Homo \& persona (a) in iure maxime differunt. Homo est, cuicumque mens ratione praedita in corpore humano contingit. Persona est homo, cum stato quodam consideratur" ${ }^{26}$. Ello había quedado expresado también en las Partidas (libro 1, tít. 23, part.4), en que se señalaba que el estado es la condición o la manera en que "los omen viven o están". Por ello, como indicaba Asso y del Río, la noción de persona aparecía íntimamente ligada a su estado, y, de lo anterior, concluía que "la Persona es: el hombre considerado en su estado; por lo que se dice que no puede haver persona sin que se considere en uno, ú otro estado". Y, conforme a ellos, se distinguieron los estatutos aplicables a nacidos y no nacidos, varones y hembras, mayores y menores de edad, jóvenes y viejos ${ }^{27}$. Por esto, también, Sala seguía reconduciendo el estado civil a la división de los hombres en libres, siervos o esclavos y aforrados (libertos) ${ }^{28}$, aunque ahora, por la variación de la estructura social de la época, agregaba otras tantas clasificaciones relevantes, como la subdivisión de los libres en nobles y plebeyos ${ }^{29}$, y en eclesiásticos o clérigos y $\operatorname{legos}^{30}$. Todas estas ideas que se extendieron, incluso, hasta reconocer un lugar en el Preußliches Allgemeines Landrecht de 1794, quedando expresado del modo que sigue; "der Mensch wird, sofern er gewisse Rechte in der bürgerlichen Gesellschaft genießt, Person gennant" 1 .

El problema, como puede observarse, es que el concepto de estado, así entendido, aún traslucía la finalidad de ofrecer una discriminación entre los hombres a efectos de conceder los diversos estatutos jurídicos reseñados, utilizando ciertas características con el fin de consagrar una diversa posición y, en consecuencia,

${ }^{25}$ ZatTi, Paolo, Di là dal velo della persona física. Realtà del corpo e diritti 'dell'uomo', en Liber Amicorum per Francesco D. Busnelli (Milán, Giuffrè, 2008), pp. 160 y 162.

${ }^{26}$ Heinnecius, Johann Gottlieb, cit. (n. 17), p. 44, traducción disponible en Heinecio, cit. (n. 17), p. 23, del siguiente modo: "Según derecho hay una gran diferencia entre hombre y persona. Hombre es un ser dotado de alma racional unida á cuerpo humano. Persona es el hombre considerado en algún estado”). Idea también presente, por ejemplo, en VulTEIUS (1605-1684), al indicar que "Persona est homo habens caput civile, quod positum est in tribus, in libértate, in civitate, in familia"; y en ThOMAsius (1655-1728), bajo la fórmula que "Persona hic denotat hominem consideratum cum suo statu".

${ }^{27}$ Asso DEL Río, Ignacio, Instituciones de derecho civil de Castilla (Madrid, Imprenta de Andrés de Sotos, 1876), pp. 1-5.

${ }^{28}$ SALA, Juan, Ilustración del derecho real de España (tercera edición corregida y arregladas las citas de las leyes a la Novísima Recopilación, Madrid, Imprenta Real, 1832), I, p. 10.

${ }^{29}$ Ibíd., I, p. 13.

${ }^{30}$ Ibíd.,I, p. 15. Lo mismo se apreciaba en Pothier, Robert J., Ouvres de Pothier. Coutume d'Orleans (París, Beaucé, Librairie de S.A.R. Mgr. Duc d'Angoulême, 1817), I, quien también ofrecía una clasificación de las personas conforme a su estado religioso (pp. 13 y 14), nobleza (p. 14), al tiempo en que descartaba cualquier referencia al status libertatis por ser ajeno a las coutumes (p. 15).

31 SATGL, Jakob F., cit. (n. 12), p. 374, nos otorga la siguiente traducción: "El hombre se dice persona en cuanto goza de determinados derechos en la sociedad civil”. 
diversos derechos y deberes enfrentado a la sociedad a la que pertenecían. El hombre en su estado, como se ofrece en esta construcción, supone una ausencia de la sustancialidad del ser humano ${ }^{32}$. Se resuelve, entonces, a modo de un orden que la ley ha impuesto para su participación en sociedad ${ }^{33}$, retumbando aún el sonido de épocas pasadas en las que dicha ordenación podía llegar al extremo de negar toda forma de capacidad natural a quien no gozaba de libertad. Esta noción de estado, en suma, estaba basada en criterios de profunda desigualdad entre los individuos, permitiendo un reconocimiento gradual de su capacidad en atención a su posición social desde una visión comunitaria ${ }^{34}$.

Tal caracterización del estado no pudo resistir los diversos replanteamientos en el propio derecho de las personas que antecedieron los textos codificados, fundados en un planteamiento iusfilosófico diverso. Para estos efectos, el pensamiento de la denominada Escuela del Derecho Natural fue reconduciendo la individualidad sobre la base de la libertad, y, conforme a ésta, de la igualdad ${ }^{35}$. Luego, la configuración del derecho privado desde una orientación individualista también supuso el desconocimiento del estado como una figura de naturaleza política consagrada, al decir de Corasanti, como instrumenti regni para la limitación de la autonomía organizativa de los individuos ${ }^{36}$. Asimismo, la observación del sujeto desde la lógica del principio de la igualdad, terminó por despreciar cualquier forma de categorización de los individuos por la crisis del sistema de los privilegios de clase justificativos del antiguo régimen ${ }^{37}$. Conforme a ello, "la división de la sociedad en estados sociales distintos, creadores de desigualdad jurídica, se considera incompatible con la democracia y es condenada por la Revolución Francesa" ${ }^{38}$, poniendo en entredicho la utilidad misma del concepto de estado civil $^{39}$, sino lograba ser de algún modo reformulado desde una posición individualista.

Por ello, la crítica a la primitiva forma de construir la noción de estado se justificó en cuanto ésta se identificaba con la propia idea de la persona, como si ella sólo pudiese entenderse en relación a otros (a modo del mentado accidente

32 Por ello, Hoyos Castañeda, Ilva Myriam, cit. (n. 10), p. 129 critica tal posibilidad en el sentido que "admitir que el hombre se configura como persona, por la posición o pertenencia a un grupo social implica, en igual forma, concebir el ser y la existencia del hombre como una mera relación”.

${ }^{33}$ Referencia que, incluso, todavía aparece en PотніER, Robert J., cit. (n. 30), I, p. 10, al indicar que "la vie civile, ou l'etat civil d'une personne, n'est autre chose que la participation d'une personne aux droits de la société civil’.

34 Corasanti, Aldo, Stato delle persone, en Enciclopedia del diritto (Varese, Giuffré, 1990), XLIII, p. 948.

35 Para una discusión sobre la materia, vid. Carpintero, Francisco, La independencia y autonomía del individuo: los origenes de la 'persona jurídica', en Anuario de Filosofía del Derecho, 4 (1987), pp. 477-522.

36 Corasanti, Aldo, cit. (n. 34), XLIII, p. 951.

37 Sobre las referencias a la nobleza en cuanto estado, DOMAT, Jean, Les loix civiles dans leur ordre natural (segunda edición, París, Pierre Auboüin, Pierre Emery et Charles Clouzier, 1697), I, pp. 44 y 45. Respecto a la pérdida de esta noción de este estado a partir de las ideas revolucionarias, CORASANTI, Aldo, cit. (n. 34), XLIII, p. 949.

38 De Castro y Bravo, Federico, cit. (n. 9), II, p. 60.

39 Rivero Ferrada, Carolina, cit. (n. 7), p. 650. 
de relación) y no en su propia individualidad. La persona pasó a perder su significación únicamente como miembro de una entidad mayor, a modo de pieza que se articulaba para la obtención de sus fines. Como concepto jurídico, entonces, la persona ya no podría entenderse como tal en tanto el ordenamiento jurídico le hubiese reconocido un estado (una determinada condición, calidad o cualidad), y, consecuentemente, ya no podría admitirse la existencia de ciertos individuos de la especie humana que -carentes de tal estado, o de los estados necesarios para estos efectos- no sólo hubiesen quedado fuera del ámbito social, sino especialmente desprovistos de personalidad y, ya desde una perspectiva puramente civil, de capacidad natural.

Por ello, sólo en la medida en la que tal separación (que hoy nos resulta tan odiosa) fue progresivamente superada, fue necesario rescatar el concepto de estado civil a fin de dar cuenta de otras tantas condiciones del hombre que, justificadas a la luz de la nueva comprensión de la vida en sociedad, podían permitir efectuar ciertas distinciones no arbitrarias en relación con su estatuto jurídico ${ }^{40}$. Se reconfigura el estado civil como un concepto que nuevamente no pretende bastarse a sí mismo, pero que ahora se plantea como un accidente de relación y resulta primeramente indicativo de una cierta pertenencia a un grupo social para observar la forma en la que ejerce sus derechos, no si tiene la posibilidad de adquirirlos. Luego, no fijándose al nivel sustancial del ser humano, depende de los diversos modos en los que tales relaciones pueden construirse y que determinan un estatuto personal en el que se desenvuelven los sujetos. Y en ello se demuestra un elemento exógeno, profundamente político, que queda al margen de la autonomía privada en la medida en que existe un evidente interés público en la elaboración del referido tejido, que, en caso contrario, carecería de una estructura uniforme, y, por tanto, se transformaría en un ovillo enmarañado que incumpliría su función.

\section{LA LECTURA DEL CONCEPTO DEL ESTADO CIVIL COMO CONTRAPUNTO A LA NOCión DE PERSONA EN EL CÓDIGO Civil CHILENo}

Como hemos indicado, la propia noción de estado civil sólo logró resistir los embistes de los nuevos parámetros sociales una vez que la propia noción de persona fuere formulada bajo criterios de profunda igualdad. En nuestra codificación civil, lo anterior se evidencia claramente de la lectura del artículo 55 CC, norma construida sobre los cimientos de la mencionada equiparación de todos los individuos de la especie humana ${ }^{41}$, evitando cualquier forma de abstracción basada

40 De Castro y Bravo, Federico, cit. (n. 9), II, p. 59.

${ }^{41}$ Lo anterior de la mano también con las elaboraciones cristianas que fueron observando a la persona en su individualidad, como se desprende de las obras de San Agustín (especialmente De Trinitatis) y de Santo Tomás, tomando este último la noción ya elaborada por BoEcio bajo la clásica formulación de "persona est naturae rationalis individua substantia". Sobre los contornos de tal evolución, vid. STAGL, Jakob F., (n. 12), pp. 395-397. Asimismo para una referencia a la base constitucional de la norma, vid. LIRA URQUieta, Pedro, El Código Civil chileno y su época (Santiago, Editorial Jurídica de Chile, 1956), p. 17. 
en criterios de diferenciación sobre su capacidad jurídica ${ }^{42}$. No nos interesa en este punto dar cuenta de las innegables dificultades que se han apreciado para la propia elaboración de un concepto jurídico de persona ${ }^{43}$, sino revisar en particular la distancia que ella se presenta con relación al estado civil. Así, en términos generales, esta visión subjetivista reconoce a la persona, sin distinción, como sujeto de derechos ${ }^{44}$, atribuyéndole una capacidad jurídica básica como medio de atribución de derechos y obligaciones ${ }^{45}$, para luego permitir una forma de graduación, no a nivel sustancial, sino accidental, en razón de su situación en el contexto social para fines diversos a los cuales el estado fue originalmente concebido ${ }^{46}$.

Consecuente con lo anterior, las nociones de persona y estado civil aparecen convenientemente diferenciadas en nuestro código, desligándose de las fuentes hispanas que se manifestaban con ánimo de unidad en las Partidas. Ello aparece con claridad por la distancia conceptual entre el citado artículo 55 y el artículo 304 CC. Aún más, la referencia a la edad, sexo, estirpe y condición en el artículo 55 CC da noticia de los parámetros usualmente utilizados en el devenir histórico para efectuar distinciones entre los seres humanos, fuesen naturales o legales. Debe destacarse el último de tales criterios (i.e., la condición), dado que éste efectúa una referencia genérica al estado ${ }^{47}$, el que, en consecuencia, termina siendo ignorado (e, incluso, descartado) para los efectos del reconocimiento de la persona. Como bien concluye Stagl, "la función del concepto de persona ha cambiado de manera determinante: ya no sirve para establecer una discriminación jurídica, sino más

${ }^{42}$ Se produce, como señala Falcón y OzCoIsi, Modesto, Exposición doctrinal del derecho civil español, común y foral (Madrid, Tipografía La Publicidad, 1987), I, p. 100, la completa identidad entre hombre y persona.

${ }^{43}$ Para estos efectos, en el contexto nacional, puede consultarse a Corral TalCiani, Hernán, El concepto jurídico de persona. Una propuesta de reconstrucción unitaria, en Revista Chilena de Derecho, 17 (1990), 2, pp. 301-321; y, en términos generales, Hoyos CASTAÑEDA, Ilva Myriam, cit. (n. 10).

${ }_{44}$ STAGL, Jakob F., cit. (n. 12), p. 375. Por eso Fabres, José Clemente, Instituciones de derecho civil chileno, en Obras completas de don José Clemente Fabres (Santiago, Imprenta y Encuadernación La Ilustración, 1912), IX, ya señalaba que la persona es un ser capaz de derechos y obligaciones.

${ }^{45}$ Corasanti, Aldo, cit. (n. 34), XLIII, p. 953.

${ }^{46}$ El único punto en que se tomaba distancia de esta nueva construcción estaba dado por la muerte civil (artículo 95 CC), conforme a la cual se terminaba la personalidad en lo referente a los derechos de propiedad, de manera que el individuo era reputado muerto para la adquisición y goce de estos derechos civiles, resultado del abrazo a la profesión en un instituto monástico reconocido por la Iglesia católica. Sobre este punto, vid. Salinas ARANEDA, Carlos, El influjo del derecho canónico en el Código Civil de la República de Chile (Valparaíso, Ediciones Universitarias de Valparaíso, 2006), pp. 128-138.

${ }^{47}$ Como nos señala Barrientos Grandón, Javier, cit. (n. 18), p. 64, durante el siglo XVI y buena parte del XVII, "se asentó la idea que, en esta sede, aquella voz [status] significaba la c o n d i c i ó n de las personas en orden a la libertad, la ciudadanía, o la familia". De ello también queda expresión en otras partes del CC, especialmente en el libro I, título I, párrafo 3, designado "Del domicilio en cuanto depende de la condición o estado civil de la persona", y así se advierte también en la definición del estado de las personas dada por EsCRICHE, Joaquín, Diccionario razonado de legislación y jurisprudencia (París, Librería de Garnier Hermanos, 1891), p. 659. 
bien para representar al hombre que se ha liberado de sus cadenas del status, que, con la ayuda del Estado de derecho liberal, puede ser faber fortunae suae" ${ }^{48}$.

El desgaje entre la noción jurídica de persona y estado impide, por de pronto, efectuar cualquier elaboración amplia de esta última, sea para identificarla con la idea general de personalidad, sea para equipararla a la noción de capacidad de goce $^{49}$. Al menos en nuestro ordenamiento, se trata de conceptos que funcionan en niveles diversos, pero no por ello completamente desconectados ${ }^{50}$. Si acaso pudiese entenderse que la idea de persona se encuentra vinculada con aquélla que le transforma en sujeto de derechos (y, por tanto, en un ente con capacidad de goce), se trata ésta de una conclusión previa a la concesión del estado civil en la forma en la que éste se define en el artículo 304 CC. De este modo, la ordenación propuesta por el estado presupone la capacidad de goce, como aptitud del hombre de ser sujeto en las relaciones de derecho ${ }^{51}$. Si esta capacidad se entiende indisolublemente unida al propio concepto de persona, como elemento esencial al mismo ${ }^{52}$, el estado civil se comporta como la enunciación genérica de ciertos elementos accidentales del ser humano que pueden ser utilizados para la configuración precisa de los derechos y obligaciones que pueden ser ejercidos o contraídos por el sujeto en razón de su posición en la estructura social.

De tal suerte, el estado se comportará a modo de síntesis de aquellas modulaciones de la capacidad de ejercicio del sujeto dimanantes de ciertos supuestos fácticos jurídicamente relevantes. Así, el estado no es indicativo de la relación jurídica en sí (esto es, la pertenencia a un cierto grupo social) ${ }^{53}$, sino sólo un elemento que permite el posicionamiento o situación del individuo ante la sociedad por el hecho de la pertenencia a dicho grupo social ${ }^{54}$. En razón de tal pertenencia, su relevancia jurídica queda condicionada a la generación de ciertas consecuencias que ya no permiten una alteración de su personalidad, sino sólo la conformación de un estatuto personal que le permita ejercer los derechos y obligaciones de los que goza de manera matizada en razón de su integración al grupo. Conforme a todo

48 STAGL, Jakob F., cit. (n. 12), p. 384.

49 Como la efectuada por Pere Raluy, José, Derecho del registro civil (Madrid, Aguilar, 1962), I, p. 12. En razón de ello Lyon Puelma, Alberto, Personas naturales (Santiago, Ediciones Universidad Católica de Chile, 2007), p. 168, concluye que el estado civil no constituye el fundamento de la personalidad.

${ }^{50} \mathrm{Al}$ efecto, Claro SOLAR, Luis, Explicaciones de derecho civil chileno y comparado. De las personas (Santiago, Imprenta Cervantes, 1926), IV, p. 7, señala que "todo individuo de la especie humana es persona, es decir, tiene la aptitud o capacidad de adquirir derechos; pero no todos los individuos se hallan en la misma situación, considerados como miembros de la asociación política a la que pertenecen”.

51 Sánchez Román, Felipe, Estudios de derecho civil (Madrid, Est. Tipográfico Sucesores de Rivadeneyra, 1911), II, p. 112.

${ }^{52}$ De ahí que LyON Puelma, Alberto, cit. (n. 49), p. 168 observe "El estado civil y la nacionalidad no son, definitivamente, elementos esenciales de la personalidad. Es cierto que solo las personas pueden tener un estado civil o una nacionalidad, pero eso no significa que ellos sean esenciales para configurar o estructurar la institución de la personalidad jurídica”.

53 Scardulla, Francesco, s.v. Stato civile, en Enciclopedia del diritto (Varese, Giuffré, 1990), XLIII, p. 939.

${ }^{54}$ Ibíd., XLIII, pp. 938-939. 
lo anterior, se produce una inversión de los conceptos. En la dimensión colectiva y pública del estado, éste se presentaba como anterior a la capacidad jurídica de modo tal que ella era observada como una consecuencia del status pleno, en sus dimensiones clásicas de libertad, ciudadanía e independencia familiar, de modo tal que la membresía o adscripción al grupo se presentaba como una pieza fundamental para su consagración. En cambio, por medio de una formulación individualista, la posición de los elementos es justamente la contraria: el reconocimiento de la capacidad jurídica es indistinto a la pertenencia a un determinado grupo, sino que emana del propio reconocimiento de la individualidad, de modo tal que el estado recoge la noción de membresía sólo a efectos de situar jurídicamente al individuo y así determinar el modo preciso en el que debe ejercer sus derechos y contraer sus obligaciones.

\section{Propuesta de una nueva lectura del concepto de estado CIVIl del artículo 304 del Código Civil}

\section{Formulación crítica de la doctrina nacional}

La tarea para elaborar nuestra propuesta sobre la correcta forma de interpretar la definición de estado civil propuesta por el artículo 304 CC, es ciertamente compleja. Andrés Bello no dejó registro expreso del origen de dicha definición, el que tampoco encuentra parangón en otros textos codificados de la época (especialmente, la codificación francesa), aunque sí puede observarse una variación en el texto con respecto a aquél contenido en el Proyecto de 1853. Al efecto, éste formulaba la definición del siguiente modo: "el estado civil es la calidad de un individuo en cuanto relativa a su capacidad para ejercer ciertos derechos o contraer obligaciones civiles", provocando la crítica que anticipábamos ha hecho la doctrina nacional al tiempo de apreciar la cercanía del concepto con la capacidad jurídica.

Ahora bien, esta ausencia no resulta en un obstáculo para lograr identificar otras tantas referencias contenidas en el propio código, como así también en otros textos jurídicos asignados a Bello ${ }^{55}$, para lograr una interpretación sistemática del concepto. Tampoco debemos despreciar las mutaciones que se presentan respecto al contexto histórico de la norma, a la que ya hemos hecho referencia, y a un cúmulo de fuentes doctrinales consultadas por el codificador en la elaboración de sus textos, utilizando, para estos efectos, principalmente doctrina francesa y el proyecto codificador español ${ }^{56}$. Conjugando tales elementos, pretendemos comprobar la hipótesis planteada en nuestra introducción, para lo cual creemos

55 Incluyendo la Ley sobre efecto retroactivo de las leyes, de 7 de octubre de 1861, cuyo proyecto fue presentado por el Presidente Manuel Montt el 27 de julio de 1859, replicando básicamente la propuesta de Andrés Bello sobre el particular. Vid. Jacsić Andrade, Iván, Andrés Bello. La pasión por el orden (Santiago, Editorial Universitaria, 2001), p. 234.

56 Deberá descartarse una influencia alemana directa, porque ésta se manifestaba críticamente a la conservación del concepto de estado civil, que se entendió que sólo se justificaba en una formulación social como la ofrecida en Roma. Por ello, la noción de estado debió ser reconstruida bajo la denominación de "causas modificativas de la capacidad", que, a partir de Savigny, se justificaron en razón a la pertenencia a ciertas agrupaciones políticas (de derecho público) y familiares (de derecho privado). 
necesario efectuar una deconstrucción de la definición, dando cuenta de sus elementos relevantes.

\section{La referencia a la calidad del individuo}

Destáquese, en primer lugar, la definición en torno a la calidad del i n d i v i d u o, la que resulta (como se expresa en las normas siguientes relativas principalmente a la prueba del estado civil) de su inclusión en una determinada organización colectiva ${ }^{57}$, que, veremos, se circunscribía al grupo familiar. Pero, como hemos señalado, no es la membresía (o la sola situación del sujeto) la que caracteriza su identidad como persona, puesto que la propia formulación del concepto presupone la individualidad. El individuo, como ya había expresado el artículo 55 CC, se reconoce como tal con independencia a toda calidad (sea natural o legal), de manera que reiteramos aquí que el estado no opera a un nivel sustancial ni permite la clasificación de los seres humanos en su significación como personas ni, en lo pertinente, como sujetos de derecho.

Chacón despreciaba este elemento de la definición por una confusión en torno a la causalidad. Así, expresaba que "el estado crea la calidad; pero esta calidad que es el efecto, es distinta del estado, que es la causa" ${ }^{58}$. El punto nos parece cuestionable desde la perspectiva de los antecedentes históricos antes aludidos, que identificaban la calidad (qualitas) con el estado desde la idea de utilizar el status como un criterio de clasificación de las personas. Asimismo, tal calidad se reconduce a la posición social, que denominaremos bajo el concepto de membresía, como una forma de integración a una determinada organización, de tal manera que es dicho status del que se derivan las consecuencias jurídicas que reseñaremos en el acápite siguiente, todas las cuales sí se configuran como un efecto de la calidad del individuo. El problema de la argumentación de Chacón se encuentra, a nuestro juicio, en que el autor continuaba dimensionando a la persona desde la perspectiva del estado, expresándolo como la posición legal que el hombre ocupa en la familia y en la sociedad ${ }^{59}$.

Asimismo, si el estado sólo diese cuenta de una forma de individualización de la persona en razón de su situación en la colectividad, como parece desprenderse de parte de la doctrina francesa sobre el punto ${ }^{60}$, se trataría de una definición

${ }^{57}$ La identificación del estado como calidad del individuo se manifiesta expresamente en Delvincourt, Claude Étienne, Institutes de droit civil français (París, Gueffier, 1808), I, p. 31, al tiempo de indicar que el estado civil es el que determina el rango que las personas deben ocupar en la ciudad o en la familia, y que, a efectos de determinar tales diversas calidades, es necesario establecer los hechos y las épocas del nacimiento, del matrimonio o de la muerte de ciertas personas. Asimismo, Rogron, Joseph Adrién, Codes francais expliqués par leurs motifs, par des examples et par la jurisprudence (París, Videcoq y Alex-Gobelet, 1836), p. 2, añadía que el estado es la posición de los ciudadanos en la sociedad, una cualidad a la cual la ley adjunta ciertos derechos y de donde resulta la capacidad.

${ }^{58}$ CHacón, Jacinto, Esposición razonada i estudio comparativo del Código Civil chileno (tercera edición, Santiago, Imprenta Nacional, 1890), p. 288.

59 Ibíd., p. 287.

${ }^{60}$ Así, Bonnecase, Julien, Las personas en el derecho civil (Bogotá, Leyer, 2005), p. 103; y Rochfeld, Judith, Les grandes notions du droit privé (París, PUF, 2011), pp. 38-41. Pensamos 
con escaso contenido técnico-jurídico, si no pudiese asociarse a éste alguna cierta consecuencia normativa. Para Ripert y Boulanger, el estado de una persona (status o conditio) se refiere a "ciertas cualidades que la ley tiene en cuenta para atribuirle efectos jurídicos. Como se debe partir del principio de la igualdad civil, sólo se designa así las cualidades particulares que parecen compatibles con este principio de igualdad. Así, las cualidades de francés, de mayor, de esposo, de hijo legítimo, son estados jurídicos. Señalar el estado de una persona, es calificarla precisando el punto de vista bajo el que se considera"61.

En nuestro ordenamiento, este primer elemento configurador del estado civil, referido a la posición del individuo en el seno de la agrupación, también presupone la acreditación de ciertos presupuestos fácticos $(v \cdot g r$., matrimonio, filiación y edad), a los que el código dedica una multitud de normas probatorias entre los artículos 305 y $320 \mathrm{CC}^{62}$; pero, como veremos, la definición del estado civil debe ser complementada con las consecuencias jurídicas propuestas en el mismo artículo 304 CC. Esto implica la necesaria articulación del estado en dos sentidos: el primero, de carácter interno, hace referencia a la calidad del individuo como parte de la agrupación (y es al que estamos haciendo ahora referencia); y el externo, que alude a su proyección respecto a la totalidad de la sociedad, o, como indica Fabres, a los extraños, dando cuenta de sus consecuencias jurídicas en general ${ }^{63}$.

Luego, si la calidad refiere a un elemento accidental, en este caso, en razón de su integración a una determinada organización, el Código Civil sólo mantiene una de las formulaciones clásicas que se configuraron a la luz del derecho romano. A la época del código ya parecía cierto que no era posible ofrecer graduaciones en torno a la idea de libertad, como tampoco de la ciudadanía ${ }^{64}$. Respecto a lo primero, la ley de libertad de vientre, de 15 octubre de 1811 ,y la aprobación de la propuesta de José Miguel Infante al Senado el 23 de junio de 1823, habían terminado por

que esta simplificación del concepto puede provenir de la regulación del estado civil en el Código Civil francés, que, carente de conceptualización, se detiene en la reglamentación de las actas del estado civil, como un mecanismo de registro público de sus hechos desencadenantes.

61 Ripert, Georges y Boulanger, Jean, Tratado de derecho civil (Buenos Aires, La Ley, 1963-1965), II/1\%, pp. 9 y 10; y Planiol, Marcel, Traité élémentaire de droit civil (París, Librairie Générale de Droit et de Jurisprudence, 1915), I, p. 154.

${ }^{62}$ En este sentido debe leerse también lo dispuesto en el artículo 1 de la ley $\mathrm{N}^{\circ} 4.808$, sobre registro civil, al disponer que "las inscripciones de los nacimientos, matrimonio, defunciones y demás actos y contratos relativos al estado civil de las personas, se harán en el Registro Civil por los funcionarios que determina esta ley". Lo anterior puesto que se está haciendo referencia a los hechos constitutivos del presupuesto fácticos que conforman el elemento esencial del estado civil, los cuales, en consideración a su relevancia, han merecido un tratamiento público.

${ }^{63}$ Fabres, José Clemente, cit. (n. 44), IX, p. 229. Por ello, el mismo autor señala que la calidad de tutor o de curador no puede constituir estado civil, puesto que no se cumpliría con el primero de los requisitos, esto es, la integración a las relaciones de familia.

${ }^{64}$ Observando, particularmente, que EsCRICHE, Joaquín, cit. (n. 47), p. 659, había indicado que el estado civil se divide en público o privado, comprendiendo el primero la libertad y la ciudadanía, de modo tal que el privado quedaba circunscrito a las relaciones emanadas del derecho de familia. 
abolir en Chile toda forma de esclavitud ${ }^{65}$, de modo tal que resultaba lógico que nuestra codificación civil silenciara toda referencia al status liberatis. Respecto a la nacionalidad, si bien el inciso segundo del artículo 55 CC dispone una división de las personas en chilenos o extranjeros, el artículo siguiente reconduce la clasificación a las normas constitucionales ${ }^{66}$, refiriéndose, en consecuencia, a la relevancia política (más no civil) de la distinción ${ }^{67}$. Lo anterior queda incluso reflejado, por oposición, en el artículo 57 del Código Civil expresa convenientemente la desestimación del punto, disponiendo que la "ley no reconoce diferencias entre el chileno y el extranjero en cuanto a la adquisición de los derechos civiles que regla este código", marcando una diferencia con la aproximación al punto por parte de la codificación francesa ${ }^{68}$. Bien podrá observarse que la referencia dada por el citado artículo 57 se refiere a la adquisición, y no al ejercicio, de los derechos civiles, pero tampoco encontramos en nuestro Código Civil limitaciones en este segundo aspecto en razón de la nacionalidad de los sujetos.

Conforme a lo anterior, se justifica que, situados en un estadio histórico que se formula en términos diversos en torno a la construcción de una comunidad mayor $^{69}$, sólo queda una reconducción del estado civil en torno a expedientes derivados del derecho de familia (status familiae), y de ahí el posicionamiento de la normativa en dicho contexto. Por ello, las críticas a la vaguedad del concepto en este punto no parecen justificadas, puesto que una lectura sistemática del

${ }^{65}$ Feliú Cruz, Guillermo, La abolición de la esclavitud en Chile (Santiago, Editorial Universitaria, Santiago, 1973).

${ }^{66}$ A la época, dispuestas en el capítulo IV de la Constitución Política de 1833.

${ }^{67}$ En este punto, CHACón, Jacinto, cit. (n. 58), p. 288, advierte la subsistencia de un estado de ciudad, pero cuya importancia debe ser reconducida al derecho público, a diferencia del estado de familia. Por ello, si bien la distinción entre chilenos y extranjeros aparece en nuestro Código Civil en los términos indicados, nos parece que en la configuración del código ella no aparece como un reconocimiento del status civitatis puesto que no se desprenden de ella diferencias en relación a la habilitación para el ejercicio de derechos y obligaciones, conforme se reconduce la noción de estado en los términos del artículo 304 del Código Civil. En este sentido, también, Barros Errázuriz, Alfredo, Curso de derecho civil. Primer año (Santiago, Imprenta Cervantes, 1907), p. 118.

${ }^{68}$ La distancia con el Code Civil es ostensible si se observa que el título I de su libro I ("De las personas") se encabeza por el artículo séptimo, conforme al cual el ejercicio de los derechos civiles es dependiente a la calidad de ciudadano, la cual se adquiere y conserva de acuerdo a las reglas constitucionales. Destáquese asimismo la preocupación del Code Napoleon por ligar el goce de los derechos civiles en razón de la calidad de francés (artículo octavo), detallando la forma en la que se integra dicha categoría. También aparece en ello la pérdida de derechos civiles precisamente en razón de la pérdida de la calidad de francés, como se expresa en los artículos 17 y siguientes del Code. En todo ello nuevamente aparece el concepto de calidad (como sinónimo de estado), rescatando las reglas del status civitatis para el goce de los derechos civiles, normas que no aparecen replicadas por en nuestra codificación civil.

${ }^{69}$ En ello, cobra fuerza la explicación de D’Aguessau, Henri F., Essai sur l'etat des personnes, en Oeuvres complètes du Chancelier D’Aguessau (París, Fantin et Compagnie, H. Nicolle, De Pelafol, 1819), IX, p. 578, al indicar que la distinción de los estados del hombre en razón de la libertad y ciudadanía se configuran como estados públicos, mientras que aquél derivado de la familia corresponde a un estado particular, distinción que ya era posible avizorar desde la idea de la triple capitis diminutio. 
ordenamiento jurídico vigente a la época del código no podría dar pie a la integración de otros conceptos, como los de la nacionalidad. Pero la referencia a la membrecía a la familia resulta innegable por dos aspectos adicionales. En primer término, por los elementos relativos a la prueba del estado civil dispuestas en el mismo título XVII del libro I, todos evidentemente relacionados con el ámbito familiar, incluyendo el matrimonio y la filiación, tanto legítima como natural. En segundo término, porque si se observa el tratamiento del punto en relación con la ley de efecto retroactivo de la ley, de 7 de octubre de 1861 (en adelante, LERL), se observa una clara distancia en el tratamiento del estado civil de los hijos legítimos y naturales (artículos 3 y 5 LERL), negando tal estado al hijo ilegítimo, quien no era considerado como parte de la familia ${ }^{70}$, y a quien sólo se asignaban derechos de alimentos (artículo 6 LERL, en relación con el libro I, título XIV CC).

En este punto, el aspecto a considerar es que el status familiae se construía en torno a las primigenias ideas de la clasificación de las personas en sui iuris y alieni iuris como forma de distinguir situaciones de dependencia e independencia ${ }^{71}$, reproduciendo "a pequeña escala, la relación entre amo y esclavo" especialmente por medio de la formulación general de la patria potestad ${ }^{72}$, como asimismo de la autoridad paterna y la potestad marital. Ya nos señalaba Domat que los hijos e hijos de familia son aquellos que se encuentran sujetos a la patria potestad, mientras los padres o madres de familia (también denominados jefes de familia), son quienes no están sujetos a dicha potestad ${ }^{73}$. Y así también Pothier señalaba que otra de las divisiones de las personas se encontraba entre quienes son "usantes de leurs droits" (en otros términos, sui iuris) y quienes se encuentran sujetos a la potestad del marido, a la patria potestad, o bajo la dirección de los tutores y curadores ${ }^{74}$.

Tal construcción queda también identificada en el mensaje del Código Civil, haciendo referencia al "estado de dependencia" para identificar los contornos de la patria potestad y de la emancipación de conformidad a la edad del hijo ${ }^{75}$, como también del párrafo $3^{\circ}$ del libro I, título I del CC, que, haciendo referencia expresa a la incidencia del estado civil en el domicilio de las personas, relaciona tales conceptos, en lo que nos interesa, con la potestad marital (artículo 71 CC) y con la patria potestad (artículo $72 \mathrm{CC}$ ). Finalmente, ello quedó claramente manifestado en la LERL, que, luego de indicar la operatoria de los cambios legislativos en referencia al estado civil, el inciso segundo de su artículo 3 dispone que "en consecuencia, las leyes de subordinación i dependencia de los cónyuges, entre padres e hijos, entre guardadores i pupilos, establecidas por una lei, serán obligatorias

70 Barros Errázuriz, Alfredo, cit. (n. 67), p. 122.

71 SavignY, Friedrich Karl von, cit. (n. 6), I, p. 332.

72 STAGL, Jakob F., cit. (n. 12), pp. 382-383.

73 Domat, Jean, cit. (n. 37), I, p. 47.

${ }^{74}$ Pothier, Robert J., cit. (n. 30), I, p. 13.

75 El mensaje se expresa del siguiente modo: "La mayor edad, fijada a los veinticinco años, emancipa por el ministerio de la ley al hijo de familia. Esto sólo mejoraría ya entre nosotros su condición, pues, como sabéis, no hay por la sola edad límite alguno para ese 'estado de dependencia' según las leyes romanas y patrias”. Lo destacado es nuestro, tanto para acreditar la identificación del estado y la condición (para los efectos de la correcta interpretación del artículo 55 CC), como para evidenciar la referencia al señalado "estado de dependencia". 
desde que ella empiece a rejir, sin perjuicio del pleno efecto de los actos válidamente ejecutados bajo el imperio de la lei anterior".

\section{Sobre las consecuencias jurídicas del estado civil}

a) Planteamiento general

Como hemos señalado, el estado civil no pretende detenerse en la singularización del individuo en razón a su membresía, sino que, en tanto concepto técnico, requiere de la configuración de consecuencias jurídicas en razón de ellas. Como explicaba D'Aguesseau, a partir de las ideas de Domat, el estado particular (derivado de las relaciones de familia) deben ser reconducidos a las reglas atinentes en materia de las obligaciones y sucesiones, y se comportaban como normas que hacen que los hombres sean considerados como capaces o incapaces en tales dimensiones $^{76}$. De este modo, se concluye que nociones tales como la pubertad o impubertad, como la de los hijos legítimos o naturales, se reconocen como calidades constitutivas del estado, que pueden ser considerados para la justificación de la capacidad o incapacidad, sea en términos generales o particulares ${ }^{77}$. También Pothier expresaba que el estatuto personal, cuyo objeto general era la regulación del estado de las personas, se refiere especialmente a la patria potestad, la tutela de los menores, la emancipación, la edad requerida para testar y la potestad marital, todas reglas, que, conforme observaremos, se referían a la capacidad de ejercicio de la mujer casada y de los hijos ${ }^{78}$.

Lo anterior también queda expresado en el artículo $304 \mathrm{CC}$, al tiempo en que dispone que tal cualidad es la que "le habilita para ejercer ciertos derechos o contraer ciertas obligaciones civiles". En este aspecto, la alusión queda evidentemente dada a la capacidad de ejercicio, en tanto la aptitud para "hacer valor los derechos, sea mediante la celebración de actos jurídicos, sea mediante la realización de ciertos hechos que son lícitos en razón del derecho que se hace valer" 79 , como se deprendía con mayor claridad en la definición contemplada en el artículo 343 del Proyecto de 1853, antes citado ${ }^{80}$. La vinculación entre ambos conceptos se puede percibir también por medio de las fuentes consultadas por Bello, destacando especialmente

${ }^{76}$ D’Aguesseau, Henri F., cit. (n. 69), IX, p. 580. No puede negarse, sobre este punto, que AlesSANDRI, SOMARRIVA y VODANOVIC, cit. (n. 3), I, p. 434, agregaban, como consecuencia del estado civil, que "en muchas ocasiones influye en la capacidad de las personas", cuestión que luego desarrollan en las pp. 434 y 435. Idea que ya había expresado BARRos ERrÁzURIZ, Alfredo, cit. (n. 67), p. 119, sobre la base de entender que el estado es la calidad de una persona que fija sus derechos y obligaciones y la capacidad legal es la aptitud o facultad para ejercitar por sí misma esos derechos. Una posición crítica sobre el punto es expresada más abajo.

77 D’Aguesseau, Henri F., cit. (n. 69), IX, p. 581.

78 Pothier, Robert J., cit. (n. 30), I, p. 2.

79 LeÓn Hurtado, Avelino, La voluntad y la capacidad en los actos jurídicos (Santiago, Editorial Jurídica de Chile, 1991), p. 232.

${ }^{80}$ Aproximación acentuada en dicho proyecto, como expresaba Claro Solar, Luis, Explicaciones [...] De las personas, cit. (n. 50), IV, p. 7, no sin criticar la reconducción puesto que "no podía ser esta la mente del sabio autor del proyecto que en los artículos siguientes de este título del código ha conservado, hablaba del estado civil de casado o viudo, del estado civil de padre o hijo legítimo, del estado civil de padre, madre o hijo natural”. 
el concepto de estado configurado por Rogron, quien precisamente señalaba que el estado es una calidad de donde resulta la capacidad ${ }^{81}$. Y se detalla, incluso con mayor cercanía en Duranton, quien exponía que el estado civil es la cualidad en razón de la cual las personas consideradas en su relación con la sociedad en general, o por la relación con la familia en particular, goza de ciertos derechos más o menos extendidos y se encuentran sometidos a deberes más o menos numerosos ${ }^{82}$.

Tal posición se plantea, luego, en Josserand, al afirmar que "l'etat commande á la capacité, mais la réciproque n'est pas vraie" ${ }^{83}$, refiriéndose a una suma de factores matizadores referidos al sexo, la edad y la filiación, o ciertos hechos desencadenantes, como el matrimonio, el divorcio, la emancipación y la adopción. Pero todo ello con el matiz, también presente en la regulación nacional, de que estos factores no se refieren al goce de ciertos derechos o el sometimiento a ciertas obligaciones, que en Duranton todavía parecían indicativos de la capacidad de goce, sino en relación con el ejercicio de los derechos y la contracción de las obligaciones ${ }^{84}$.

Como comprobación de lo anterior, también debe tenerse a la vista la disposición prevista en el artículo 15 No 1 CC, al tiempo en que, fijando el estatuto personal en el ámbito del efecto de las leyes en el espacio, distingue claramente el estado de las personas y su capacidad de ejercicio ${ }^{85}$. Sobre el particular, las fuentes consultadas por Bello se encuentran, por una parte, en el artículo 3 del Code Napoleon, que efectuaba igual distinción entre el estado y la capacidad, de manera que las normas referidas a ellos seguían a los franceses con independencia a su residencia en el extranjero, y, por la otra, la explicación dada por Delvincourt a la norma en comento, que identificaba las leyes personales como aquellas relativas al matrimonio, a la patria potestad y a la mayoría de edad ${ }^{86}$. El propio Bello destacaba el sentido de la disposición señalando que "en jeneral, las leyes relativas al estado civil i capacidad de los ciudadanos, ejercen su imperio sobre ellos donde quiera que residan. Tales son las que determinan la edad en que se puede contraer matrimonio, la necesidad de consentimiento de los padres para contraerlo, los impedimentos que lo hacen ilícito o nulo, i las obligaciones a que por la unión conyugal se sujetan ambos consortes. Lo mismo se aplica a las leyes que reglan la legitimidad de los hijos, los años de la pubertad i de la edad mayor, la capacidad o incapacidad de los menores para ciertas funciones, i los requisitos i formalidades de la emancipación" ${ }^{87}$.

${ }^{81}$ Rogron, Joseph Adrién, cit. (n. 57), p. 2.

82 Duranton, Alexandre, Cours de droit français suivant le Code Civil (París, G. Thorel Libraire y Guilbert Libraire, 1844), p. 215.

83 Josserand, Louis, Cours de droit civile (Paris, Librairie du Recueil Sirey, 1930), p. 149.

${ }^{84}$ Claro Solar, Luis, Explicaciones [...] De las personas, cit. (n. 50), IV, p. 7, expresa: "el estado civil influye en la capacidad para el ejercicio de los derechos; pero no debe confundirse con ella. Así la mujer mayor de edad que se casa pierde la capacidad que tenía como consecuencia de su mutación de estado civil, mientras permanezca bajo la potestad de su marido".

${ }^{85}$ Villarroel Barrientos, Carlos y Villarroel Barrientos, Gabriel, Derecho internacional privado (Santiago, Editorial Jurídica de Chile, 2015), p. 216.

${ }^{86}$ Delvincourt, Claude Étienne, cit. (n. 57), I, p. 11.

${ }^{87}$ Bello, Andrés, Obras completas de don Andrés Bello. Derecho internacional (Santiago, Imprenta de Pedro G. Ramírez, 1886), X, p. 88. 
De ahí la referencia también dada a la validez de los actos ejecutados en razón de un determinado estado civil, como propone el inciso segundo del artículo 3 de la LERL, la que no podría ser reconducida a la capacidad de goce, sino precisamente a la capacidad de ejercicio, como elemento necesario para la validez de los actos y contratos en los términos previstos en el artículo 1445 CC. Pero obsérvese que no se trata necesariamente de dicha capacidad de ejercicio en toda su extensión, como se sugeriría de su comparación con el inciso $2^{\circ}$ del artículo 1445 CC, para lo cual tiene relevancia la alusión a la voz "ciertos", como un adjetivo limitativo de los derechos que pueden ser ejercidos y las obligaciones que pueden ser contraídas en razón del elemento habilitante de la calidad del individuo. De lo anterior se presupone que el estado civil no es necesariamente indicativo de una incapacitación general de ejercicio, sino que como elemento a considerar para ofrecer matices en razón de la particular posición del individuo en la organización y que, en razón de la misma, el ejercicio de ciertos derechos y la contracción de ciertas obligaciones queda sujeta a reglas especiales.

b) Formulación particular en materia de derecho de familia y sus consecuencias legales

En el modelo del código original, nos parece que la conclusión planteada en el acápite anterior aparecía de forma prístina. Como señala Lira Urquieta, el criterio del Código Civil consistía en el traslado a los textos legales de la doctrina canónica en materia de familia, de tal suerte que su jefatura quedaba situada en el marido, padre, a su vez, de los hijos comunes que son frutos del matrimonio. A partir de lo anterior, se le asigna la representación legal de los hijos menores y de la mujer sujeta a una incapacidad relativa por el hecho mismo del matrimonio ${ }^{88}$. Veamos separadamente estos aspectos y su incidencia en materia de capacidad y, en consecuencia, de la validez de los actos o contratos.

\section{i) respecto al matrimonio}

En razón de la situación de la mujer casada, el estado civil derivado del matrimonio -con la necesaria reconducción a las reglas de la sociedad conyugalimplicaba la incapacidad relativa de la mujer casada (artículo 1447 inc. $3^{\circ} \mathrm{CC}$ ). Ello, precisamente en razón de la idea de dependencia al marido, como aparece formulada en Domat ${ }^{89}$, justificada en el derecho consuetudinario francés ${ }^{90}$, y reconocible también en las Leyes de Toro y en la Novísima Recopilación, fundada siempre en la idea de la potestad marital ${ }^{91}$. Al efecto, y ya en torno a la norma

${ }^{88}$ Lira Urquieta, Pedro, cit. (n. 41), p. 17.

89 Domat, Jean, cit. (n. 37), I, p. 38.

90 Sobre la permanencia de una incapacidad fundada en la potestad marital, aun después de la visión individualista y libertaria de la Revolución Francesa, vid. AlESSANDRI Rodríguez, Arturo, Tratado práctico de la capacidad de la mujer casada, de la mujer divorciada perpetuamente $y$ de la mujer separada de bienes (Santiago, Imprenta Universitaria, 1940) p. 21, justificándola en la influencia de Napoleón Bonaparte y su criterio autoritario acerca de las relaciones entre marido y mujer.

${ }^{91}$ Ibíd., p. 22. Clara referencia a dicha potestad se encuentra en la indicación de la subordinación y dependencia de la mujer respecto al marido, conforme se expresa en el artículo 3 LERL. 
del Código Civil, Barros Errázuriz indicaba que la incapacidad de la mujer se fundaba en la naturaleza del matrimonio y a la sujeción a la potestad del marido, quien debía ser considerado como el jefe de familia. A ello, agregaba, que "no se concibe sociedad sin autoridad; y en la sociedad doméstica, la autoridad reside en el marido" "2 . Así también, Alessandri explicaba que la mujer quedaba "en una situación de dependencia y subordinación respecto al marido, al extremo que no solo le debe obediencia (art. 131), sino que éste es su representante legal (art. 43) y puede, por lo mismo, ejercer en su nombre los derechos que le competan y celebrar toda clase de actos jurídicos", para luego mencionar ciertas excepciones a dicho régimen ${ }^{93}$.

De ello se desprende, como hacía Claro Solar, que "uno de los efectos principales que produce el matrimonio es la p o t e s t a d $\mathrm{m}$ a rit a l y la consiguiente incapacidad de la mujer" ${ }^{94}$. Pero dicha incapacidad se sujetaba, al mismo tiempo, a la lógica de la sociedad conyugal como régimen general de bienes derivado del matrimonio, de tal suerte que resulta en una "consecuencia de la comunidad de intereses que crea entre los esposos la unión conyugal y de la necesidad de confiar a uno de ellos la dirección de estos intereses" ${ }^{15}$; reconducción que también es admitida por Alessandri Rodríguez, al señalar que, incluso después de las reformas de la ley $\mathrm{N}^{\circ} 5.521$, "el verdadero y único fundamento de esta incapacidad es la comunidad de bienes que crea el matrimonio entre los cónyuges, como lo demuestra de un modo inequívoco el hecho que desaparecida esa comunidad por el divorcio perpetuo o por la separación total, la mujer recupera su plena capacidad, no obstante que en el segundo caso el marido conserva la potestad marital sobre su persona" ${ }^{\text {. }}$.

Veamos, entonces como se formulaba este acceso a la plena capacidad (y modulada potestad marital), en el artículo 149 CC, alusivo a los casos en los que la referida dependencia encontraba excepciones. La primera, en el caso que la mujer ejerciere una profesión, industria u oficio, caso en el cual, conforme al artículo $150 \mathrm{CC}$, se sujetaba a una presunción de autorización del marido en lo referente a tal profesión o industria mientras no interviniese reclamación o protesta del marido. En este caso, como se observa, no hay una verdadera excepción a la situación de dependencia de la mujer, puesto que la norma sólo operaba bajo el régimen de una presunción de la autorización requerida por el artículo 137 CC y, como tal, podía desarticularse en atención a la citada reclamación del marido. De ahí que el ejercicio de la profesión no pudiese implicar una modificación real de la capacidad de ejercicio de la mujer, y, por tanto, de su estado civil.

El segundo caso estaba dado por el divorcio perpetuo (artículo $173 \mathrm{CC}$ ), de

92 Barros Errázuriz, Alfredo, cit. (n. 67) p. 54.

93 Alessandri Rodríguez, Arturo, cit. (n. 90), p. 2.

${ }^{44}$ Claro Solar, Luis, Explicaciones de derecho civil chileno y comparado. De las Personas, (Santiago, Imprenta Cervantes, 1929), II, p. 74. Lo anterior es reforzado por el mismo autor (p. 78), al indicar que "la razón de la incapacidad de la mujer casada se encuentra, por consiguiente, en el matrimonio que la somete a la potestad del marido".

${ }^{9}$ Ibíd., II, p. 78.

96 Alessandri Rodríguez, Arturo, cit. (n. 90), p. 24. 
acuerdo al cual la mujer divorciada administraba, con independencia al marido, los bienes que había sacado del poder de éste, o que después del divorcio había adquirido. De ello resultaba que, en tal caso, sí operaba una verdadera excepción al artículo 137 CC, y, como tal, desaparecía la situación de dependencia del marido en términos de capacidad. Pero en este caso, si bien la regla evitaba la alusión al e stado de divorciado, esta no resultaba desconocida por el CC, que advertía la noción del "estado de divorcio" en el artículo 497 N 10 CC para los efectos de las incapacidades para el ejercicio de las guardas. Aquí, la supresión de la potestad marital se manifestaba de manera amplia, de forma que, recuperando la mujer su plena capacidad, era necesario concebir un nuevo estado (de divorciado) para fijar su nueva posición en el contexto del derecho de familia, en lo que se refería, preferentemente, a sus extensiones patrimoniales.

Finalmente, en el en el supuesto de separación total de bienes, que en el contexto original del código sólo era admisible por resolución judicial (libro I, título IV, párrafo 4), la referencia se daba al "estado de separación" (artículo 160 CC), para efectos de disponer la contribución que cada uno de los cónyuges debían efectuar para satisfacer las necesidades familiares conforme a sus facultades económicas. Lo anterior, acto seguido a indicar que por el referido estado de separación la mujer separada de bienes no necesitaba la autorización del marido para los actos y contratos relativos a la administración y goce de lo que separadamente administra (artículo 159 CC). La alusión a un nuevo estado aparece nuevamente indicativo de la modulación de la potestad marital, recibiendo la correspondiente reconducción a la alteración del status.

Cabe observar, en consecuencia, que tanto en el caso del divorcio perpetuo como en la separación de bienes se producía la disolución de la sociedad conyugal (artículo 1764 CC), desactivando la justificación dada a la regla de la incapacidad relativa de la mujer casada, aunque debe tenerse presente que no por ello la potestad marital cesaba en iguales términos. De este modo, en el divorcio perpetuo (artículo 170 CC) ella desaparecía por completo, al tiempo que en la simple separación de bienes ella sólo terminaba en lo relativo a la administración de los bienes de la mujer y en referencia a la enajenación de sus bienes muebles. Sin embargo, subsistía para la representación de la mujer en sus actuaciones judiciales (salvo los casos del artículo $136 \mathrm{CC}$ ), y en todo lo relativo a los actos de disposición de los bienes inmuebles (artículo 159 CC). Por ello, como indicaba Barros Errázuriz, "la mujer separada de bienes tiene una capacidad intermedia entre el estado de la capacidad del régimen normal del matrimonio y el estado de capacidad de la mujer divorciada" 97 . Bien podrá indicarse que los estados de separado y divorciado no aparecen reflejados en las normas dispuestas en el título XVII del libro I, pero deberá considerarse que, luego de la definición del estado civil del artículo 304 $\mathrm{CC}$, las reglas se refieren a la configuración de los diversos modos de prueba de dichos estados, los que en los casos antes referidos quedan simplificados puesto que siempre resultaban de una sentencia judicial (artículos 152 y $170 \mathrm{CC}$ ).

${ }^{97}$ Barros Errázuriz, Alfredo, cit. (n. 67), p. 124. 


\section{ii) respecto a la filiación}

En relación con los hijos legítimos, la referencia estaba dada, en el aspecto patrimonial, a la extensión de la patria potestad hasta la emancipación (libro I, títulos X y XI CC), para lo cual era también esencial la identificación de la edad de los hijos ${ }^{98}$; y, en el aspecto personal, la regla del artículo 235 CC que disponía que el padre, y en su defecto la madre, tendrían el derecho de elegir el e s t a d o o profesión futura del hijo. Esta norma debe ser coordinada con los artículos 105 y $107 \mathrm{CC}$ en referencia a la necesidad del consentimiento del padre legítimo, o, a su falta, de la madre legítima, para la celebración del matrimonio (como limitación al ius connubii). Por su parte, respecto a los hijos naturales, categoría que no permitía la aplicación a las reglas de la patria potestad (libro I, título XII CC), la limitación no se articulaba entonces como una sujeción patrimonial, sino solo personal, lo que quedaba particularizado, nuevamente en línea de la capacidad, en la necesidad de obtener el consentimiento de aquel padre o madre que lo hubiese reconocido a efectos de contraer matrimonio, en caso de ser menor de veinticinco años (artículo $108 \mathrm{CC}{ }^{99}$. De ahí también que, conforme al artículo 279 inciso final CC, se hacía asimismo aplicable a los hijos naturales la regla del artículo 235 CC antes señalada.

\section{iii) respecto a las reglas de capacidad, en general}

Ahora bien, la redirección del estado a la capacidad también aparece expresada en el tratamiento de la nulidad de los actos y contratos. Como se aprecia fácilmente de dichas normas, su validez queda condicionada por aquellos elementos que se han dispuesto en razón de su especie (artículo 1681 CC) o naturaleza (artículo 1682 CC), o a la calidad o estado de las partes (artículos 1681 y 1682 CC), dando los primeros lugar a la nulidad absoluta, y los segundos a la nulidad relativa. La referencia al estado de las personas debe ser entendida en alusión al artículo 304 CC, pero con una advertencia adicional. Todas estas normas deben entenderse reconducidas, a su vez, al artículo 1445 CC, regla que, como sabemos, es indicativa de los requisitos previstos genéricamente para que una persona se obligue válidamente en virtud de una declaración de voluntad. Si observamos el referido artículo, veremos que, en sí mismo, no contiene alusiones directamente expresivas del estado de las personas, por lo que aparecería una disonancia entre todas las normas antes referidas. Ello, a menos que comprendamos que la referencia a la calidad o estado de las partes tienen algún grado de incidencia en los requisitos previstos en el mentado artículo $1445 \mathrm{CC}^{100}$. De su observación, y coordinado a su vez con las disposiciones de su inciso segundo y de los dos artículos siguientes,

98 Domat, Jean, cit. (n. 37), I, p. 47.

99 De ahí la referencia a este punto en la identificación de los efectos del estado civil, en torno a la construcción del estatuto personal en el ámbito del artículo $15 \mathrm{~N}^{\circ} 1 \mathrm{CC}$, que comentaremos más adelante.

100 De ahí que la elaboración de la nulidad relativa por parte de Claro Solar, Luis, Explicaciones de derecho civil chileno y comparado. De las obligaciones (III) (Santiago, Editorial Nascimento, 1939), XII, p. 582, aparezca continuamente dirigida a la capacidad legal, como articulación de la referencia a la calidad o estado de las partes. 
podrá obtenerse que la mentada incidencia se da precisamente en referencia a las reglas de la capacidad ${ }^{101}$, lo que se observa con bastante claridad por la alusión de la incapacidad relativa general de la mujer casada ${ }^{102}$. Respecto a los hijos, en cambio, las reglas aparecen imbricadas con la edad de los sujetos, que, conforme se dispone en el artículo 314 CC, también se configura como un elemento para la correcta construcción del estado civil ${ }^{103}$. Sólo una apreciación separada deberá darse con respecto a los impúberes, que, conforme al artículo 1447 inc. $1^{\circ} \mathrm{CC}$, son considerados como incapaces absolutos, de modo tal que sus actos no generan, ni aún, obligaciones naturales (artículo 1447 inc. $2^{\circ} \mathrm{CC}$ ). Con relación a estos, a pesar de que el vicio se refiere a la calidad o estado de las partes, el artículo 1682 inc. $2^{\circ} \mathrm{CC}$, lo reconduce igualmente a la nulidad absoluta, pero ello se explica puesto que, en este caso, el legislador estima que no existe una voluntad que sea jurídicamente apropiada para la validez del acto, si no, acaso, una sola apariencia de voluntad que no se encuentra sustentada en el discernimiento y conciencia, de manera que la cuestión se reconduce también a otro de los elementos señalados en el artículo $1445 \mathrm{CC}$, como es el de la voluntad propiamente tal ${ }^{104}$. Dicho lo anterior, nos parece que la referencia al estado de las personas en sede de nulidad no hace sino cerrar el ciclo de cuanto estábamos expresando, en términos que su referencia debe entenderse generalmente alusiva a una modulación de la capacidad sobre la base de la dependencia o independencia familiar, y que, en el primer caso, resulta generalmente desencadenante de un vicio de nulidad relativa (salvo la excepción antedicha), precisamente por su incidencia en las reglas de la capacidad de ejercicio, como ya había quedado expresado en el artículo 304 CC.

101 En este sentido, Alessandri Besa, Arturo, La nulidad y la rescisión en el derecho civil chileno (Santiago, Editorial Jurídica de Chile, 2008), II, p. 19, reconduciendo el tema a las denominadas for malid a des habilit a n t e s, dado que "mediante su cumplimiento, se permite que personas que adolecen de alguna incapacidad civil, puedan manifestar válidamente su voluntad". Ello, para luego indicar que "esta autorización produce como efecto la integración de la capacidad del incapaz, lo que permite celebrar el contrato o ejecutar el acto con plena validez" (p. 89).

${ }^{102} \mathrm{El}$ sistema de nulidad previsto en el CC se encuentra evidentemente influenciadas por la obra de Delvincourt. Este aspecto es particularmente relevante puesto que, al tratar de la justificación de la incapacidad de la mujer casada, la norma debe ser comprendida en razón de la potestad marital. Al efecto, a juicio del citado autor, la justificación de la norma del código se encuentra en que se trata de una mujer casada y no autorizada, disponiéndose la nulidad como un medio para impedir la violación de las reglas de obediencia que debe al marido. DeLvinCOURT, M., Cours de Code Napoléon (Paris, Chez P. Gueffier, Imprimeur-Libraire, 1813), II, p. 373.

103 De ahí que las reglas relativas a la capacidad de los hijos debían ser coordinada con aspectos alusivos a la edad en diversos aspectos. La edad es la que permite la clasificación de las personas en infantes o niños, impúberes y adultos (distinguiendo a su vez, menor adulto y mayor adulto), en los términos del artículo 26 CC. También resulta relevante para la capacidad matrimonial (artículos 106, 107, 108, 111 y 112 CC), para la administración de la sociedad conyugal por parte del marido (artículo 148 CC), para efectos de la emancipación (artículo 241 y $266 \mathrm{~N}^{\circ} 3 \mathrm{CC}$ ), respecto de la habilitación de edad (artículos 297 y siguientes CC), para las limitaciones para ejercer como tutores o curadores (artículo $500 \mathrm{CC}$ ), entre otras.

104 Claro Solar, Luis, Explicaciones de derecho civil chileno y comparado. De las obligaciones (II) (Santiago, Editorial Nascimento, 1937), XI, p. 13; HURTAdo LEÓN, Avelino, cit. (n. 79), p. 235; AlessANDri BesA, Arturo, cit. (n. 101), II, p. 430. 
c) Sobre los supuestos derechos y obligaciones emanados del estado civil

Un punto adicional a tratar se refiere a si resulta efectivo que las consecuencias del estado civil deben ser reconducidas a un aspecto adicional, como es la configuración de ciertos derechos y obligaciones que de él derivarían ${ }^{105}$. Así se ha planteado en la doctrina nacional, como queda expresado por Claro Solar al señalar que "el estado civil imprime carácter, por decirlo así; da al individuo una situación permanente emanada del hecho que lo determina y le confiere por el solo ministerio de la ley un conjunto de derechos y obligaciones inherentes a su persona"; por Barros Errázuriz, al señalar que "el derecho civil sólo se ocupa del estado civil de las personas entendiendo por tal la calidad o condición de la persona en orden a sus relaciones de familia, en cuanto esa calidad le origina derechos y obligaciones de orden privado"106; y por Alessandri, Somarriva y Vodanovic, indicando que el estado civil confiere o impone determinados derechos y obligaciones civiles en el orden de las relaciones de familia del individuo ${ }^{107}$. A partir de ello, por ejemplo, Ramos Pazos deduce que "del estado civil de casado derivan una serie de derechos y obligaciones entre los cónyuges (fidelidad, ayuda mutua, socorro, etc.); lo mismo del estado civil de padre (autoridad paterna, patria potestad, alimentos, derechos hereditarios, etc.)"108; al tiempo que Rivero Ferrada señala que "el estado civil fija determinadas relaciones entre sujetos de derecho y de ello se derivan una serie de prerrogativas y obligaciones" ${ }^{\text {"109. }}$.

La cuestión no aparece claramente manifestada en el contexto del Código Civil. De hecho, además que ello no se expresa como una consecuencia de una determinada calidad del individuo en el artículo 304 CC, ya se ofrece una distancia conceptual entre ambos elementos en razón del artículo 15 del Código Civil. Al efecto, esta norma forma parte del denominado estatuto personal en el ámbito del derecho internacional privado, distingue en sus numerales, por una parte, el estado, sujetando este aspecto a las leyes patrias para todos los chilenos con independencia a su residencia o domicilio en el extranjero, y, por la otra, las obligaciones y derechos que nacen de las relaciones de familia, limitándose, en este caso, sólo a respecto a los cónyuges y parientes chilenos. Este segundo numeral no tiene un reconocimiento expreso en las fuentes consultadas por Bello, como son el artículo 3 del Code Napoleon, el artículo 7 del Proyecto de García Goyena y las obras de Delvincourt ${ }^{110}$.

Como se desprende de la norma en comento, todos los mencionados derechos y obligaciones se asignan en razón de las relaciones de familia, que la propia regla

105 Una formulación intermedia se encuentra en FABREs, José Clemente, cit. (n. 44), IX, p. 83, al señalar que el estado civil "es el conjunto de derechos y obligaciones señalados por la ley a la calidad o condición particular de un individuo en sus relaciones de familia o e n $\mathrm{s} u$ capacidad para el ejercicio de los derechos civiles" (el destacado es nuestro).

106 Barros Errázuriz, Alfredo, cit. (n. 67), p. 118.

107 Alessandri, Somarriva y Vodanovic, cit. (n. 3), I, pp. 433 y 434.

108 Ramos Pazos, René, cit. (n. 1), II, p. 528.

109 Rivero Ferrada, Carolina, cit. (n. 7), p. 659.

110 Cit. n. 86. 
reconecta al matrimonio y al parentesco ${ }^{111}$. Así, los deberes matrimoniales se integran al contrato de matrimonio en razón del estatuto jurídico que éste plantea a modo de dar cuenta de los contornos de la comunidad de vida y sus fines reflejados en la definición del artículo $102 \mathrm{CC}$, configurados en el libro I, título VI, párrafo 1 del CC. Por su parte, los derechos hereditarios tampoco parecen ser resultado directo del estado civil. Para ello, deben observarse conjuntamente las reglas del artículo 15 No 2, y 998 CC, los cuales tampoco hacen referencia directa al status, aunque el último sí efectúe referencias a los derechos hereditarios, a la porción conyugal y a los alimentos.

Los derechos sucesorios se configurarán entonces en torno al matrimonio (en el código original, mediante la asignación de una porción conyugal, en los términos de los artículos 959, N 5, 988, 998, 1167 y al libro II, título V, párrafo 2, todos del CC) o en razón del parentesco (principalmente, a nivel de legítimas o mejoras, en los términos de los artículos 1182 y 1195 CC, y de los órdenes de sucesión en el contexto de la sucesión intestada, cuyos integrantes son genéricamente aludidos en el artículo 983 CC), ocurriendo algo similar en relación con el derecho de alimentos (artículo 321 CC). Si no fuere de este modo, creemos, no existiría una uniformidad de criterios en la asignación de ambos derechos, que no incluyen únicamente a cónyuges e hijos (quienes sí podrían tener un estado civil que les relaciona con el causante, el alimentante o el alimentario, según el caso), sino que se extienden a otras tantas personas con las quienes únicamente existe una relación de parentesco, pero no necesariamente estado civil, en los términos descritos en los artículos 27 a 33 CC.

Sin perjuicio de lo anterior, una lectura diferente podría propiciarse en torno a lo dispuesto en el artículo 3 inciso primero, LREL, al disponer que "el estado civil adquirido conforme a la lei vijente a la fecha de su constitucion, subsistirá aun que esta pierda despues su fuerza; pero los derechos i obligaciones anexos a él, se subordinarán a la lei posterior, sea que esta constituya nuevos derechos u obligaciones, sea que modifique o derogue los antiguos". Si bien estos derechos y obligaciones anexos podrían comprenderse bajo los conceptos amplios propuestos por la doctrina nacional, creemos que la norma debe ser leída en su contexto. Sin embargo, el inciso segundo de la misma norma reconduce su significado a las reglas de subordinación y dependencia entre cónyuges y entre padres e hijos, refiriéndose al "pleno efecto de los actos validamente ejecutados bajo el imperio de un lei anterior". De ello se deduce que los derechos y obligaciones a los que se refiere el inciso primero tampoco son alusivos a los deberes matrimoniales, derechos sucesorios o alimentos, sino a los efectos de los actos jurídicos realizados válidamente por el marido o mujer, conforme a las reglas de la sociedad conyugal; por el padre

${ }^{111} \mathrm{Al}$ efecto, no nos parece correcta la reconducción efectuada por ALESSANDRI, SOMARRIVA y VodANOVIC, cit. (n. 3), I, p. 434, entre el estado civil y parentesco, en el sentido de que el primero daría origen al segundo. Si bien operan en niveles similares, dada su reconducción a las relaciones de familia, no existe una vinculación causal entre éstos. Ello queda de manifiesto, por ejemplo, en la situación del parentesco ilegítimo (artículos 29, 32 y 33), considerando especialmente que el CC no reconocía un estado civil a los hijos de dañado ayuntamiento ni a los hijos simplemente ilegítimos (artículos 36 a 39 CC). 
legítimo, en razón de la autoridad paterna y de la patria potestad, o por los tutores y curadores en referencia a las guardas ${ }^{112}$.

Ahora bien, si la referencia al estado civil sólo parece indicativo de una situación de dependencia familiar, de ello se también se concluye que no parece efectivo que el estado civil pueda ser calificado como un atributo de la personalidad ${ }^{113}$. Como hemos indicado, por una parte, no opera en la línea de la capacidad de goce, y, por la otra, porque ella se formula desde la idea de la dependencia y subordinación de sus integrantes. Así, la sola integración a un grupo familiar no supondría necesariamente un estado civil, sino en la medida en que ella logre la alteración de las reglas de la capacidad de ejercicio ${ }^{114}$. A partir de lo anterior, se desprende, por ejemplo, que el individuo soltero y emancipado no tendría estado civil, lo que se colige también de la ausencia de medios probatorios en las reglas que siguen al artículo 304 y a una completa falta de referencia en la LERL.

\section{Conclusiones}

1. El concepto de estado civil siempre ha requerido reformulaciones en atención a que se trata de una abstracción que supone la pertenencia del sujeto a un cierto grupo social. De tal suerte, en la medida en que los modelos asociativos (generales y particulares) se han visto reconfigurados a lo largo de la historia, la propia noción de status ha debido adecuarse a los planteamientos políticos y sociales subyacentes. De tal modo, incardinado inicialmente en la lógica de que "la persona es el hombre en su estado", este último implicaba un dimensionamiento únicamente colectivo del ser humano a partir del cual podían efectuarse discriminaciones que afectasen su personalidad y, en consecuencia, su régimen jurídico aplicable.

112 Ello se deduce también de otras tantas reglas dispuestas en la LERL que se refieren directamente a los derechos aludidos por la doctrina nacional. Al efecto, se contienen reglas especiales y diversas en referencia a los derechos de usufructo legal (artículo 4), a las ventajas y obligaciones del hijo natural (artículo 5), al derecho de alimentos del hijo ilegítimo (artículo 6), al derecho de representación (artículo 20).

113 En contra, por ejemplo, Somarriva Undurraga, Manuel, cit. (n. 2), p. 601; Ramos Pazos, René, cit. (n. 1), I, p. 527, Ducci Claro, Carlos, cit. (n. 1), p. 131. Una visión crítica al punto se encuentra en VARgas Viancos, Juan Enrique, Atributos de la personalidad y garantías constitucionales, en Barros BourIE, Enrique (coord.), Familia y personas (Santiago, Editorial Jurídica de Chile, 1991), pp. 150-151 “el estado civil de las personas mal pude ser entendido como un elemento necesario para el desenvolvimiento del individuo por si solo, como tampoco algo inherente a la calidad humana [...] El estado civil más se parece a un ordenamiento jurídico de roles impuestos por el derecho para atribuir determinadas consecuencias jurídicas, en que el individuo debe adscribirse a alguno, ya sea voluntariamente (en el caso del matrimonio para pasar de soltero a casado) o involuntariamente (en el caso de la muerte del cónyuge para pasar de casado a viudo)".

114 De ahí la crítica de Ducci Claro, Carlos, cit. (n. 1), p. 131, conforme a las críticas tradicionales al concepto propuesto por el artículo $304 \mathrm{CC}$, al señalar que "Por otra parte, la habilidad de un individuo para ejercer derechos o contraer obligaciones puede ser muy diversa, aunque su estado civil permanezca invariado; así un mayor de edad, hijo legítimo, soltero, tiene plena capacidad, pero si cae en demencia, su capacidad va a desaparecer, aunque no varía en nada su estado civil". 
En cambio, al tiempo en que el derecho se observa desde la individualidad, la persona se aprecia como un ente en sí mismo, sin posibilidad de discriminación en la línea sustancial. Por ello, ahora el estado sólo puede ser utilizado para fines accidentales, tales como su afectación a la capacidad de ejercicio.

2. Este replanteamiento puede observarse en la separación del Código Civil de sus antecedentes hispanos, que fueron consolidándose a partir de las ideas del status y de la capitis diminutio en Roma. Ello se aprecia en la enorme distancia conceptual entre la noción de persona (artículo 55 CC) y de estado civil (artículo 304 CC). Este último aparece desplazado en la configuración de la personalidad y pasa a ocupar una justificación diversa, limitada ahora a la integración de un determinado grupo familiar. En ello subyacen reglas que pretenden replicar los criterios distintivos de los sui iuris y alieni iuris, aunque en clave más moderna.

3. Apreciada a partir de las normas del derecho de familia original, la definición de estado civil alude a las diversas y variables modulaciones de la capacidad de ejercicio de los individuos en razón de su integración a la unidad familiar. Lo anterior, justificado a la época del código mediante una formulación normativa en la que, sea por el hecho del matrimonio, sea en razón de la filiación, se consagraban efectos directamente condicionantes de la capacidad de ejercicio de los sujetos, a través de la regulación original de la autoridad marital y la sociedad conyugal, por una parte, y de la autoridad paterna y la patria potestad, por la otra. Todas ellas, configurando una situación de dependencia y subordinación de la mujer al marido y de los hijos respecto al padre, o, a su falta (y sólo en algunos casos), a la madre. Conforme a lo anterior, el matrimonio se formulaba como un elemento determinante para la conformación del estado; no un estado en sí mismo, sino como fundamento de otros estados, como los derivados de la original autoridad marital y autoridad paterna, desplegándose esta última en términos paralelos con la patria potestad y autoridad paterna respecto a los hijos de familia (filiación legítima).

\section{BiBLIOGRAFÍA}

Alessandri Besa, Arturo, La nulidad y la rescisión en el derecho civil chileno (Santiago, Editorial Jurídica de Chile, 2008), II.

Alessandri Rodríguez, Arturo, Tratado práctico de la capacidad de la mujer casada, de la mujer divorciada perpetuamente y de la mujer separada de bienes (Santiago, Imprenta Universitaria, 1940).

Alessandri Rodríguez, Arturo; Somarriva Undurraga, Manuel; Vodanovic Haklicka, Antonio, Tratado de derecho civil. Partes preliminar y general (Santiago, Editorial Jurídica de Chile, 1998), I.

Asso DEL Río, Ignacio, Instituciones de derecho civil de Castilla (Madrid, Imprenta de Andrés de Sotos, 1786).

Barrientos Grandón, Javier, Sobre el 'espacio y el 'tiempo' y el 'estado de las personas. Una mirada desde la historia del derecho, en Meccarelli, Massimo y Solla Sastre, María Julia (eds.), Spatial and Temporal Dimensions for Legal History. Research Experiences and Itineraries (Frankfurt am Main, Max Planck Institute for European Legal History, 2016), pp. 63-99. 
Barros Errázuriz, Alfredo, Curso de derecho civil. Primer año (Santiago, Imprenta Cervantes, 1907).

Bello, Andrés, Obras completas de don Andrés Bello. Derecho internacional (Santiago, Imprenta de Pedro G. Ramírez, 1886), X.

BonNeCASE, Julien, Las personas en el derecho civil (Bogotá, Leyer, 2005).

Carpintero, Francisco, La independencia y autonomía del individuo: los orígenes de la 'persona jurídica', en Anuario de Filosofía del Derecho, 4 (1987), pp. 477-522.

ChaCón, Jacinto, Esposición razonada i estudio comparativo del Código Civil chileno (Santiago, tercera edición, Imprenta Nacional, 1890), I.

Claro Solar, Luis, Explicaciones de derecho civil chileno y comparado. De las personas (Santiago, Imprenta Cervantes, 1926), IV.

-- Explicaciones de derecho civil chileno y comparado. De las personas (Santiago, Imprenta Cervantes, 1929), II.

-- Explicaciones de derecho civil chileno y comparado. De las obligaciones (II) (Santiago, Editorial Nascimento, 1937), XI.

-- Explicaciones de derecho civil chileno y comparado. De las obligaciones (III) (Santiago, Editorial Nascimento, 1939), XII.

Corasanti, Aldo, s.v. Stato delle persone, en Enciclopedia del diritto (Varese, Giuffré, 1990), XLIII, pp. 948-977.

Corral Talciani, Hernán, El concepto jurídico de persona. Una propuesta de reconstrucción unitaria, en Revista Chilena de Derecho, 17 (1990), 2, pp. 301-321.

D’Aguessau, Henri F., Essai sur l'etat des personnes, en Oeuvres complètes du Chancelier D’Aguessau (París, Fantin et Compagnie, H. Nicolle, De Pelafol, 1819), IX, pp. 572-628.

De Castro y Bravo, Federico, Derecho civil de España (Madrid, Instituto de Estudios Políticos, 1952), II.

Delvincourt, Claude Étienne, Institutes de droit civil français (Paris, Gueffier, 1808), I.

Delvincourt, M., Cours de Code Napoléon (Paris, Chez P. Gueffier, ImprimeurLibraire, 1813), II.

Domat, Jean, Les loix civiles dans leur ordre natural (segunda edición, París, Pierre Auboüin, Pierre Emery et Charles Clouzier, 1697), I.

Ducci Claro, Carlos, Derecho civil. Parte general (cuarta edición, Santiago, Editorial Jurídica de Chile, 2015).

Duranton, Alexandre, Cours de droit français suivant le Code Civil (Paris, G. Thorel Libraire y Guilbert Libraire, 1844).

ESCRICHE, Joaquín, Diccionario razonado de legislación y jurisprudencia (París, Librería de Garnier Hermanos, 1891).

FABres, José Clemente, Instituciones de derecho civil chileno, en Obras completas de don José Clemente Fabres (Santiago, Imprenta y Encuadernación La Ilustración, 1912), IX.

FALCÓN y OzCOISI, Modesto, Exposición doctrinal del derecho civil español, común y foral (Madrid, Tipografía La Publicidad, 1897), I.

Feliú Cruz, Guillermo, La abolición de la esclavitud en Chile (Santiago, Editorial Universitaria, 1973).

GuZMÁn BRITO, Alejandro, La igualdad natural de todos los hombres en el pensamiento jurídico romano de la época clásica, en Revista de Estudios Histórico-Jurídicos, 14 (1991), pp. 17-42. 
HeInecio, Elementos del derecho romano según el orden de las instituciones (traducción de José Vicente) (Madrid, Imprenta de Don Pedro Sanz y Sanz, 1842).

HeInEccius, Johann Gottlieb, Elementa iuris civilis secundum ordinem institutionum (Giessa, Krieger, 1767).

Hoyos Castañeda, Ilva Myriam, El concepto jurídico de persona (Pamplona, Ediciones Universidad de Navarra, S.A., 1989).

Jacsić Andrade, Iván, Andrés Bello. La pasión por el orden (Santiago, Editorial Universitaria, 2001).

Josserand, Louis, Cours de droit civile (Paris, Librairie du Recueil Sirey, 1930).

KaSER, Max, Derecho romano privado (Madrid, Reus, 1968).

LeÓn Hurtado, Avelino, La voluntad y la capacidad en los actos jurídicos (Santiago, Editorial Jurídica, 1991).

Lira Urquieta, Pedro, El Código Civil chileno y su época (Santiago, Editorial Jurídica de Chile, 1956).

Lyon Puelma, Alberto, Personas naturales (Santiago, Ediciones Universidad Católica de Chile, 2007).

Pere Raluy, José, Derecho del registro civil (Madrid, Aguilar, 1962), I.

Pothier, Robert J., Ouvres de Pothier. Coutume d'Orleans (Paris, Beaucé, Librairie de S.A.R. Mgr. Duc d'Angoulême, 1817), I.

Planiol, Marcel, Traité Élémentaire de droit civil (Paris, Librairie Générale de Droit et de Jurisprudence, 1915), I.

Ramos Pazos, René, Derecho de familia (séptima edición actualizada, Santiago, Editorial Jurídica de Chile, 2010), II.

Ripert, Georges y Boulanger, Jean, Tratado de derecho civil (Buenos Aires, La Ley, 1963-1965), II/1º.

Rivero Ferrada, Carolina, El estado civil, en Del Picó Rubio, Jorge (dir.), Derecho de familia (Santiago, Thomson Reuters, 2016), pp. 647-664.

RochFelD, Judith, Les grandes notions du droit privé (París, PUF, 2011).

Rogron, Joseph Adrién, Codes français expliqués par leurs motifs, par des examples et par la jurisprudence (Paris, Videcoq y Alex-Gobelet, 1836).

SALA, Juan, Ilustración del derecho real de España (tercera edición corregida y arregladas las citas de las leyes a la Novísima Recopilación, Madrid, Imprenta Real, 1832), II.

Salinas Araneda, Carlos, El influjo del derecho canónico en el Código Civil de la República de Chile (Valparaíso, Ediciones Universitarias de Valparaíso, 2006).

Sánchez Román, Felipe, Estudios de derecho civil (Madrid, Est. Tipográfico Sucesores de Rivadeneyra, 1911), II.

SAVIGNY, Friedrich Karl von, Sistema del derecho romano actual (trad. Jacinto Mesía y Manuel Poley, segunda edición, Madrid, Centro Editorial de Góngora, 19631965), I.

Scardulla, Francesco, s.v. Stato civile, en Enciclopedia del diritto (Varese, Giuffré, 1990), XLIII, pp. 938-948.

Somarriva Undurraga, Manuel, Derecho civil. Derecho de familia (Santiago, Dirección General de Prisiones, 1933).

StAGL, JaKов F., De cómo el hombre llegó a ser persona: los origenes de un concepto jurídicofilosófico en el derecho romano, en Revista de Derecho de la Pontificia Universidad Católica de Valparaiso, 45/2 (2015), pp. 373-401.

VARGAS VIANCOS, Juan Enrique, Atributos de la personalidad y garantías constituciona- 
les, en Barros Bourie, Enrique (coord.), Familia y personas (Santiago, Editorial Jurídica de Chile, 1991), pp. 145-164.

Villarroel Barrientos, Carlos y Villarroel Barrientos, Gabriel, Derecho internacional privado (Santiago, Editorial Jurídica de Chile, 2015).

Vodanovic Haklicka, Antonio, Manual de derecho civil. Parte preliminar y general (Santiago, LexisNexis, 2003).

Zatti, Paolo, Di là dal velo della persona física. Realtà del corpo e diritti 'dell'uomo', en Liber Amicorum per Francesco D. Busnelli (Milán, Giuffrè, 2008), pp. 121-170. 